\title{
Comparing models of microbial-substrate interactions and their response to warming
}

\author{
Debjani Sihi $^{1, a}$, Stefan Gerber ${ }^{1}$, Patrick W. Inglett ${ }^{1}$, and Kanika Sharma Inglett ${ }^{1}$ \\ ${ }^{1}$ University of Florida, Soil and Water Science Department, Gainesville, Florida, USA \\ ${ }^{a}$ now at: Appalachian Laboratory, University of Maryland Center for Environmental Science, Frostburg, Maryland, USA \\ Correspondence to: Debjani Sihi (dsihi@umces.edu)
}

Received: 9 June 2015 - Published in Biogeosciences Discuss.: 10 July 2015

Revised: 22 February 2016 - Accepted: 2 March 2016 - Published: 21 March 2016

\begin{abstract}
Recent developments in modelling soil organic carbon decomposition include the explicit incorporation of enzyme and microbial dynamics. A characteristic of these models is a positive feedback between substrate and consumers, which is absent in traditional first-order decay models. With sufficiently large substrate, this feedback allows an unconstrained growth of microbial biomass. We explore mechanisms that curb unrestricted microbial growth by including finite potential sites where enzymes can bind and by allowing microbial scavenging for enzymes. We further developed a model where enzyme synthesis is not scaled to microbial biomass but associated with a respiratory cost and microbial population adjusts enzyme production in order to optimise their growth. We then tested short- and long-term responses of these models to a step increase in temperature and find that these models differ in the long-term when shortterm responses are harmonised. We show that several mechanisms, including substrate limitation, variable production of microbial enzymes, and microbes feeding on extracellular enzymes eliminate oscillations arising from a positive feedback between microbial biomass and depolymerisation. The model where enzyme production is optimised to yield maximum microbial growth shows the strongest reduction in soil organic carbon in response to warming, and the trajectory of soil carbon largely follows that of a first-order decomposition model. Modifications to separate growth and maintenance respiration generally yield short-term differences, but results converge over time because microbial biomass approaches a quasi-equilibrium with the new conditions of carbon supply and temperature.
\end{abstract}

\section{Introduction}

Traditional soil organic matter decomposition models are based on first-order kinetics, where decomposition scales to the pool size. The scaling factor represents recalcitrance of a specific pool and is modified by soil temperature, moisture, and other soil properties (e.g. van Veen et al., 1984; Parton et al., 1987; Molina et al., 1990; Li, 1996; Chertov and Komarov, 1997). Recent modelling efforts have specifically included catalysis of polymeric soil organic carbon to dissolved organic carbon (DOC) by extracellular enzymes. This depolymerisation step is thought to be a rate-limiting step in organic matter decomposition processes (Schimel and Weintraub, 2003; Fontaine and Barot, 2005).

In traditional models, microbes are only considered as a simple donor-controlled pool (i.e. microbial biomass has no impact on decomposition) or in an implicit manner (Gerber et al., 2010). In contrast, in microbial models, decomposition rates become a function of enzyme activity that is linked to microbial biomass (Allison et al., 2010; German et al., 2012). This leads to more complex dynamics because decomposers feed back into soil organic matter degradation via microbial enzyme production affecting depolymerisation. This positive feedback between microbial biomass and depolymerisation causes soil organic carbon stocks and microbial biomass to oscillate after a perturbation (Li et al., 2014; Wang et al., 2014). Nevertheless, microbial decomposition models have been shown to improve the prediction of soil carbon and perform well when compared to decomposition experiments (Lawrence et al., 2009; Wieder et al., 2013, 2014a, b, 2015b). Furthermore, when compared to traditional first-order models, microbial models also display an attenuated loss of soil 
organic matter to warming (Allison et al., 2010; Wieder et al., 2013).

Moreover, the response of soil organic matter to warming is very sensitive to microbial carbon use efficiency (CUE) because this parameter and its climate sensitivity define the fraction of carbon remaining in the soil as processed organic matter vs. carbon removed via respiratory $\mathrm{CO}_{2}$ (Allison et al., 2010; Frey et al., 2013; Kivlin et al., 2013; Tucker et al., 2013; Sinsabaugh et al., 2013; Wang et al., 2013; Li et al., 2014). Temperature dependence of CUE is typically not considered in traditional decomposition models (but see Frey et al., 2013), rather the ratios between respired $\mathrm{CO}_{2}$ and the transfer to different quality pools are mostly constant parameters or vary based on soil texture, soil recalcitrance, and organic or inorganic nutrient content (Parton et al., 1987; Gerber et al., 2010). Microbial respiration can be partitioned into a series of carbon expenditures that do not contribute to growth. These expenditures include growth respiration, maintenance respiration, respiratory cost for enzyme production, and overflow respiration (Manzoni et al., 2012; Moorhead et al., 2012). Each type of respiratory carbon expenditure may differ in its response to temperature.

Respiration may be parameterised based on different microbial properties. For example, maintenance respiration is assumed to scale with microbial biomass (Chapman and Gray, 1986; Fontaine and Barot, 2005) while growth respiration may scale to the amount of new tissues built. On the other hand, overflow respiration occurs during stoichiometric adjustment (Russell and Cook, 1995; Schimel and Weintraub, 2003; Frost et al., 2005; Franklin et al., 2003), whereas costs related to enzyme production may be governed by microbial demand and substrate availability and quality, resource diffusion, and microbial diversity (Allison, 2005). This differentiation can impact the dynamics of the microbial biomass: for example, maintenance respiration costs would be incurred even in the absence of carbon uptake, which can lead to a reduction in microbial biomass. In contrast, growth respiration is only due when substrate for growth is available. Because of the explicit and mechanistic link between microbial activity and soil organic matter degradation, inclusion of microbial models in Earth system models may have the potential to ultimately reduce uncertainty in climate-carbon feedback in the face of climate change because of the explicit link between microbial activity and soil organic matter degradation (Todd-Brown et al., 2012, 2013; Wieder et al., 2015a).

As microbial models are considered for broader application in Earth system models, it is essential to analyse and understand their structure and their dynamics. Here, we compare a series of microbial decomposition models with each other. Specifically, we analyse feedbacks between depolymerisation and microbial growth, consider constraints on depolymerisation and enzyme-substrate interactions, investigate the parameterisation of microbial enzyme productivity, and address the representation of microbial respiration and CUE.

Our main questions are as follows:

a. How do different model implementations of depolymerisation affect the feedback between microbial biomass and soil organic matter if subjected to warming?

b. How does the consideration of functional respiration terms (growth, maintenance, and carbon acquisition expenditures) affect decomposition dynamics?

We organise the paper in the following way. In the next section, we introduce three simple models that differ in their representation of depolymerisation. Each model will be further modified for a different representation of microbial dynamics and respiration. To analyse model behaviour, we will evaluate the response of respiration, microbial biomass, CUE, and soil organic matter to a step increase in temperature. We will then discuss the models' behaviour and compare their results with the dynamics of a traditional first-order model.

\section{Materials and methods}

\subsection{Model descriptions}

We first introduce three model families that differ in the way depolymerisation is handled.

In all models, the set-up consists of a single soil organic matter pool and a single microbial pool (Fig. 1). All models also implicitly take into account interaction between enzymes and substrate that results in depolymerisation of substrate into a DOC pool on which microbes can feed. Enzyme-substrate reactions are based on Michaelis-Menten kinetics (see Appendix A, Michaelis-Menten kinetics with enzyme denaturation). We do not consider a specific enzyme pool, nor a specific DOC pool, but assume that the enzyme and DOC pools are in a quasi-steady state (see Appendix A, DOC and enzyme dynamics). Thus, the amount of enzyme produced equals the amount of enzyme decay at every time step. Similarly, the amount of DOC produced is the same as the amount of DOC consumed by microbes. In contrast to Allison et al. (2010) but congruent with German et al. (2012), there is no "free" DOC; both fresh litter and microbial necromass need to be depolymerised before they can be ingested by microbes. In all models depolymerisation and microbial respiration are temperature dependent, causing increased depolymerisation and reduced microbial CUE with warming.

\subsubsection{Base models}

The tendency (derivative with respect to time) for soil organic carbon and microbes in all of the models is described 
by

$\frac{\mathrm{d} S}{\mathrm{~d} t}=I+\lambda_{\mathrm{d}} \cdot M-D$,

$\frac{\mathrm{d} M}{\mathrm{~d} t}=D \cdot \varepsilon-\lambda_{\mathrm{d}} \cdot M$,

where $S$ and $M$ are the soil organic matter and the microbial pool, respectively, $I$ is the input of fresh litter, $\lambda_{\mathrm{d}}$ is the death rate of microbes, $D$ is the rate of depolymerisation, and $\varepsilon$ is the microbial CUE.

\section{Forward M-M model (FWD)}

In the forward model (FWD), depolymerisation is represented as a Michaelis-Menten process and stems from the simple microbial-enzyme decomposition model as proposed by Allison et al. (2010) and modified by German et al. (2012) (Fig. 1a).

$D=\frac{V_{\max , \mathrm{FWD}} \cdot S \cdot M}{K_{\mathrm{m}}+S}$,

where $D$ is the rate of depolymerisation, $V_{\max , F W D}$ is the maximum depolymerisation rate, and $K_{\mathrm{m}}$ is the halfsaturation constant of enzymes. Appendix A shows the derivation of this function based on enzyme-substrate dynamics.

\section{Diminishing return (REV) model}

In Appendix B, we derive two depolymerisation models which show a diminishing increase in depolymerisation as microbial mass increases. These models include (a) a case where microbes are scavenging for free enzymes and (b) where potential sites for enzyme-substrate reactions are finite. The implementation of these factors leads to a reverse Michaelis-Menten type model (REV) as in Schimel and Weintraub (2003):

$D=\frac{V_{\mathrm{max}, \mathrm{REV}} \cdot S \cdot M}{K_{\mathrm{e}}+M}$,

where $V_{\max , \mathrm{REV}}$ is the maximum depolymerisation rate for this model and $K_{\mathrm{e}}$ is a half-saturation constant that determines the diminishing return function. In the cases developed in the Appendix, $K_{\mathrm{e}}$ incorporates factors indicating the finite sites for enzyme substrate interactions (Appendix B, model with limited available substrate) or the efficiency with which microbes scavenge for free extracellular enzymes (Appendix $\mathrm{B}$, microbial consumption of enzymes). A version of the reverse Michaelis-Menten model has also been derived for the case where an enzyme can adsorb to only a fraction of soil organic matter due to inaccessible binding sites due to surface limitation or physical protection (Wang and Post,
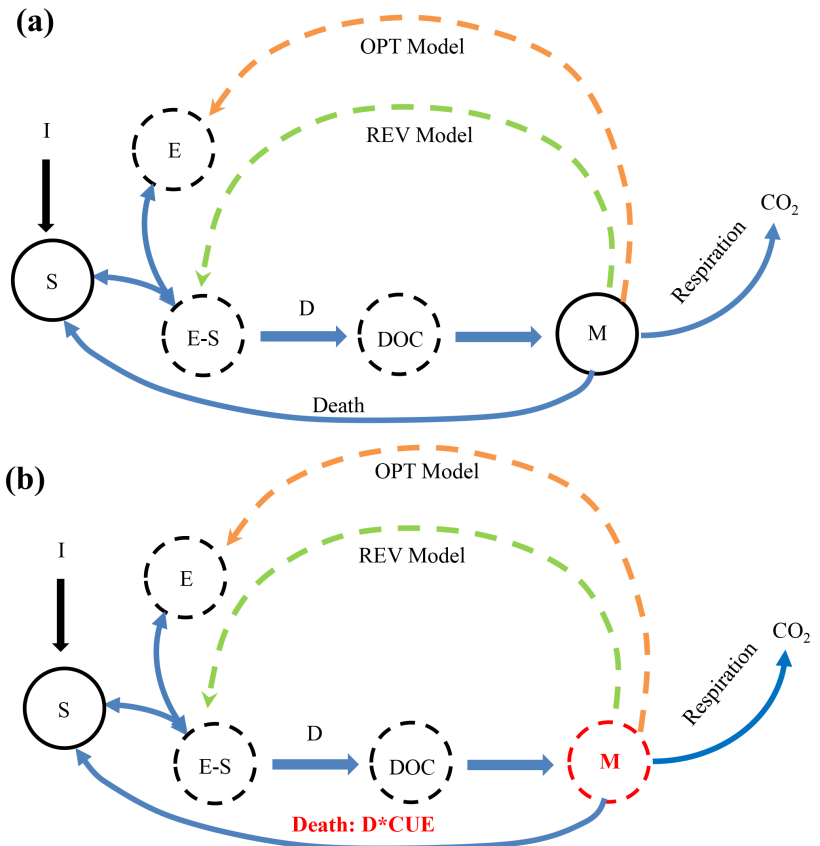

(c)

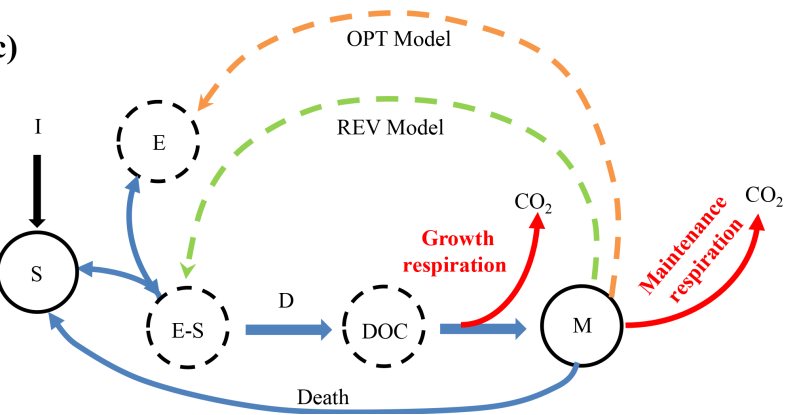

Figure 1. Conceptual diagrams of our microbial-enzyme models. The difference across the models is in the formulation of depolymerisation of soil organic matter $(S)$, where the FWD model is based on German et al. (2012), the REV model considers diminishing return, and the OPT model includes optimised enzyme production to maximise microbial growth. $E, S, E-S, D$, DOC, and $M$ represent enzyme, substrate, enzyme-substrate complex, depolymerisation, dissolved organic carbon, and microbial biomass carbon, respectively. $I$ denotes input from fresh litter and $D$ represents depolymerisation. Solid lines represent material (carbon) flow and dashed lines represent information flow affecting enzyme concentration (in microbial enzyme predation in the REV model and enzyme production rate in OPT models). $E, E-S$, and DOC pools were implicitly represented in the model but not explicitly simulated based on the assumption of quasi-steady state. We analyse the different models in three ways: (a) comparison among different parameterisations of depolymerisation (FWD, REV, and OPT models); (b) a second suite of simulations operate under the assumption that microbes are instantaneously in steady state with substrate delivery (similar to the treatment of enzymes and DOC, for REV and OPT models only, indicated by dashed outline of the pools); (c) a third series of simulations considered partitioning between a biomass-dependent maintenance respiration and a growth respiration that scales to newly built tissues, applied to all (FWD, REV, and OPT) models. 
Table 1. Key features of the microbial decomposition models and subsequent modifications presented in this study.

FWD model: German et al. (2012)

Modification: FWD model with maintenance respiration

As FWD model but microbial respiration is partitioned into temperature-insensitive

growth and temperature-sensitive maintenance respiration terms.

REV model: depolymerisation and uptake relative to microbial biomass decreases with increasing $M$ (diminishing return mechanism)

Modification: REV model with equilibrium microbes

As REV model but fast microbial adjustments.

Modification: REV model with maintenance respiration

As REV model but maintenance respiration added.

OPT model: optimisation of microbial enzyme production to maximise microbial growth and consideration of carbon costs associated with enzyme synthesis.

Modification: OPT model with equilibrium microbes

As OPT model but fast microbial adjustments.

Modification: OPT model with maintenance respiration

As OPT model but maintenance respiration added.

FOD mode

First-order decomposition model, modified to account for temperature-sensitive carbon use efficiency.

2013). A major difference from the FWD model is the inclusion of the amount of microbial biomass in the denominator in lieu of soil organic matter. Therefore, the depolymerisation per unit biomass decreases as biomass increases, plateauing at $V_{\max , \mathrm{REV}} \cdot S$ (diminishing return).

\section{Optimised enzyme production (OPT) model}

In our OPT model, we relax the condition that microbial enzyme production scales to microbial biomass, an assumption that is present in many microbial models and which is also assumed in the FWD and the REV model above. Instead, we probe a model where microbial enzyme production is optimised for growth. Optimized enzyme production in the OPT model is motivated by microbial competition (Allison, 2005), which allows microbes to succeed if microbial enzyme production allows the highest possible return. Optimisation only has meaningful results for the case of limited substrate availability (i.e. a diminishing return, possibly through constraints at potential sites for enzyme-substrate reaction) and if there is a cost associated with microbial enzyme production.

Depolymerisation as a function of enzyme production can be represented by

$D(P)=\frac{P \cdot V_{\max , \mathrm{OPT}} \cdot S}{K_{\mathrm{p}}+P}$.

$V_{\max }$, OPT is the maximum rate of depolymerisation, $P$ is the enzyme production rate, and $K_{\mathrm{p}}$ carries information on the affinity of the enzyme for the substrate and longevity of the enzyme (see Appendix $\mathrm{C}$ for full derivation of depolymerisation in the OPT model).
Microbial growth $(G)$ is as in previous models but accounts for carbon expenditure of enzyme production:

$G=\varepsilon \cdot((D(P)-P c)$,

where $c$ is the respiratory cost per unit enzyme produced (Schimel and Weintraub, 2003).

Optimising growth by setting $\frac{\mathrm{d} G}{\mathrm{~d} P}=0$ yields

$D=V_{\max , \mathrm{OPT}} \cdot S-\sqrt{K_{\mathrm{p}} \cdot c \cdot V_{\max , \mathrm{OPT}} \cdot S}$.

And the cost per unit carbon depolymerised is then

$$
\frac{P c}{D}=\sqrt{\frac{K_{\mathrm{p}} \cdot c}{S \cdot V_{\max , \mathrm{OPT}}}} .
$$

\section{Quasi-steady-state (QSS) microbe models}

While the previous models are fairly simple, we further reduce the complexity by removing microbial biomass as a state variable but instead consider $M$ at a quasi-steady state (QSS). In the QSS microbe models, the microbial uptake at each time step is thus equal to the microbial carbon loss via death or respiration (Fig. 1b). This is identical to our treatment of DOC and enzymes, where production and removal of these substances are always balanced. This simplification is motivated by the fact that microbial biomass turns over much faster than soil organic matter, and therefore microbial biomass adjusts much faster to changes in environmental conditions than soil organic matter itself. The fast turnover 
Table 2. Quasi-steady-state values for microbial biomass $(M)$, and decomposition on the short or fast timescale (at any given $S$ ) and "true" long-term equilibria for $M$ and $S$ across the models. Note that, for simplicity, we did not substitute $S$ in the long-term microbial equilibrium for the OPT model.

\begin{tabular}{|c|c|c|c|c|}
\hline \multirow[t]{2}{*}{ Model } & \multicolumn{2}{|c|}{ Short or fast timescale } & \multicolumn{2}{|l|}{ Long timescale } \\
\hline & $M$ & Decomposition & $S$ & $M$ \\
\hline FWD & no solution* & no solution* & $\frac{\lambda_{\mathrm{d}} K_{\mathrm{E}}}{V_{\max , \mathrm{FWD}} \varepsilon-\lambda_{\mathrm{d}}}$ & $\frac{I \varepsilon}{(1-\varepsilon) \lambda_{\mathrm{d}}}$ \\
\hline REV & $\frac{V_{\max , \operatorname{Rev}} S \varepsilon-K_{M} \lambda_{\mathrm{d}}}{\lambda_{\mathrm{d}}}$ & $\left(V_{\max , \operatorname{REV}} S-K_{M} \lambda_{\mathrm{d}} / \varepsilon\right)$ & $\frac{I}{V_{\max , \operatorname{REV}(1-\varepsilon)}}+\frac{K_{M} \lambda_{\mathrm{d}}}{V_{\max , \operatorname{REV} \varepsilon}}$ & $\frac{I \varepsilon}{\lambda_{\mathrm{d}}(1-\varepsilon)}$ \\
\hline OPT & $\frac{(X-Y)^{2} \varepsilon}{\lambda_{\mathrm{d}}}$ & $X^{2}-X Y$ & $\begin{array}{l}\frac{1}{2 V_{\max , \mathrm{OPT}}(1-\varepsilon)^{2}}\left[-Y(2 \varepsilon-1) \sqrt{4 I Y(1-\varepsilon)+Y^{2}}\right. \\
\left.+(1-\varepsilon)\left(2 I-2 \varepsilon Y^{2}\right)+Y^{2}\right]\end{array}$ & $\frac{(X-Y)^{2} \varepsilon}{\lambda_{\mathrm{d}}}$ \\
\hline
\end{tabular}

$X=\sqrt{S V_{\max , \mathrm{OPT}}}, Y=\sqrt{K_{P} \cdot c}$

requires $\lambda_{\mathrm{d}}=\frac{V_{\max , \mathrm{FWD}} S \varepsilon}{S+K_{E}}$

of $M$ compared to $S$ allows microbial biomass to (quasi)equilibrate with the current level of soil organic matter (see also Menge et al., 2009).

In our QSS microbe models, we solve $\frac{\mathrm{d} M}{\mathrm{~d} t}=0$, in order to obtain a quasi-steady-state microbial biomass, $\bar{M} . \bar{M}$ replaces the state variable $M$ in the functions for depolymerisation and microbial death. We note that this is only possible for the REV and the OPT model as the FWD model yields no solution for $M$ in $\frac{\mathrm{d} M}{\mathrm{~d} t}=0$. The QSS microbe models effectively become a one-pool model, where depolymerisation is not a direct function of microbial biomass but an expression of $S$ and a series of parameters. Table 2 (see formulations for short or fast timescale) shows the quasi-steady state for $M$, and the resulting depolymerisation function for the QSS microbe models. $\bar{M}$ can be diagnosed at each time step based on $S$ and parameters that determine depolymerisation and microbial turnover (Table 2, second column). In the QSS microbe models, a fraction $(1-\varepsilon)$ of depolymerisation is immediately recycled back into the soil organic matter pool; thus, the dynamics of the soil pool become

$$
\frac{\mathrm{d} S}{\mathrm{~d} t}=I-(1-\varepsilon) \cdot D .
$$

In turn, depolymerisation is immediately partitioned into respiration and a returning carbon flux, which mimics microbial death.

\subsubsection{Partitioning between maintenance and growth respiration}

While the dynamics of the soil organic matter pool remain the same as in the base model set-up, we alter all models (FWD, REV, OPT) to treat growth and maintenance respiration as separate processes (Fig. 1c). Partitioning of microbial respiration into growth and maintenance respiration charac- terises the microbial pool as follows:

$\frac{\mathrm{d} M}{\mathrm{~d} t}=\left(D-\lambda_{\mathrm{r}} \cdot M\right)(1-g)-\lambda_{\mathrm{d}} \cdot M$,

where $g$ is the growth respiration fraction and $\lambda_{\mathrm{r}}$ is the maintenance respiration rate. The separation of microbial respiration into growth and maintenance terms is motivated by similar formulations in other microbial (Beefting et al., 1990; Van Bodegom, 2007), vegetation growth (Foley et al., 1996; Cannell and Thornley, 2000; Arora, 2002; Thornley, 2011; Pretzsch et al., 2014), and ecosystem-scale (Sistla et al., 2014) models. Growth respiration is applied after requirements for maintenance respirations are met and is proportional to newly built microbial tissues. Maintenance respiration (respiration related to non-growth components) is typically proportional to microbial biomass (Van Bodegom, 2007).

\subsubsection{First-order decomposition (FOD) model}

The last model represents the structure of traditional decomposition models such as CENTURY (Parton et al., 1987) or Roth-C (Coleman and Jenkinson, 1996) and their derivatives, where decomposition is considered as a first-order reaction:

$\frac{\mathrm{d} S}{\mathrm{~d} t}=I-S \cdot k \cdot(1-\varepsilon)$,

where $k$ is the first-order decomposition constant. The two major differences between our first-order decomposition (FOD) model and traditional models are that we consider only a single carbon pool, whereas traditional models consider multiple pools with different turnover times that feed into each other. We also consider a temperature-dependent CUE on top of a temperature-dependent processing rate $(k$; see "Parameterisation and implementation" section). This increases the fraction of carbon processed with warming to become $\mathrm{CO}_{2}$. Respiration $(R)$ is then

$R=S \cdot k \cdot(1-\varepsilon)$. 
Table 3. Parameters used in microbial decomposition models. (In the model list, we provide only those parameters where modifications have been made.)

\begin{tabular}{|c|c|c|c|c|}
\hline Parameter & Unit & Value & Description & Source \\
\hline \multicolumn{5}{|l|}{ FWD model } \\
\hline I & $\mathrm{mg} \mathrm{Scm} \mathrm{cm}^{-3} \mathrm{~h}^{-1}$ & 0.001 & Input of fresh litter & $\begin{array}{l}\text { German et } \\
\text { al. }(2012)\end{array}$ \\
\hline$\lambda_{\mathrm{d}}$ & $\mathrm{h}^{-1}$ & 0.0005 & Death rate of microbes & \\
\hline$V_{\max , \mathrm{FWD}, 0}$ & $(\mathrm{mg} \mathrm{M})^{-1} \mathrm{~h}^{-1}$ & 0.0049 & Maximum catalytic rate at $15^{\circ} \mathrm{C}$ & \\
\hline$Q_{10}, V_{\max , \mathrm{FWD}}$ & - & 1.9 & $Q_{10}$ of maximum catalytic rate & \\
\hline$K_{\mathrm{m}}$ & $\mathrm{mg} \mathrm{S} \mathrm{cm}{ }^{-3}$ & 270 & Half-saturation constant at $15^{\circ} \mathrm{C}$ & \\
\hline$\varepsilon_{0}$ & - & 0.39 & Microbial growth efficiency at $15^{\circ} \mathrm{C}$ & \\
\hline$\varepsilon_{\text {slope }}$ & ${ }^{\circ} \mathrm{C}^{-1}$ & -0.016 & Microbial growth efficiency temperature slope & \\
\hline \multicolumn{5}{|c|}{ FWD model with maintenance respiration } \\
\hline$\lambda_{\mathrm{r}, 0}$ & $\mathrm{~h}^{-1}$ & 0.0006 & Maintenance respiration at $15^{\circ} \mathrm{C}$ & This study \\
\hline$Q_{10, \lambda \mathrm{r}}$ & - & 2.2 & $Q_{10}$ of maintenance respiration & \\
\hline$G$ & - & 0.24 & Growth respiration coefficient & \\
\hline \multicolumn{5}{|l|}{ REV model } \\
\hline$V_{\max , \mathrm{REV}}$ & $\mathrm{h}^{-1}$ & $2.61 \times 10^{-5}$ & Maximum catalytic rate at $15^{\circ} \mathrm{C}$ & This study \\
\hline$K_{\mathrm{e}}$ & $\mathrm{mg} \mathrm{Mcm}{ }^{-3}$ & 0.68 & Half-saturation constant at $15^{\circ} \mathrm{C}$ & \\
\hline \multicolumn{5}{|l|}{ OPT model } \\
\hline$V_{\max , \mathrm{OPT}}$ & $\mathrm{h}^{-1}$ & $1.71 \times 10^{-5}$ & Maximum catalytic rate at $15^{\circ} \mathrm{C}$ & This study \\
\hline$\mu$ & - & $0,0.1,0.5$ & $\begin{array}{l}\text { Enzyme production costs (as } \% \text { of decomposi- } \\
\text { tion at } 15^{\circ} \mathrm{C} \text { steady state) }\end{array}$ & \\
\hline$K_{\mathrm{p}} \cdot c$ & $\operatorname{mg~Scm}{ }^{-3} h^{-1}$ & $0,1.64 \times 10^{-5}, 4 \times 10^{-4}$ & $\begin{array}{l}\text { Combined cost and the half-saturation constants } \\
\text { at } \mu=0,0.1 \text {, and } 0.5 \text {, respectively. }\end{array}$ & \\
\hline \multicolumn{5}{|l|}{ FOD model } \\
\hline$k^{*}$ & $\mathrm{~h}^{-1}$ & $1.71 \times 10^{-5}$ & First-order decay constant at $15^{\circ} \mathrm{C}$ & This study \\
\hline
\end{tabular}

$* k$ in FOD model is identical to $V_{\max , \mathrm{OPT}}$ in OPT model.

\subsection{Temperature response}

We implement the response of decomposition to warming by modifying the depolymerisation and the microbial respiration.

In the FWD, REV and OPT model, $V_{\max }$ is modified as

$V_{\max , i}(\Delta T)=V_{\max , i} \cdot Q_{10}^{\left(\frac{\Delta T}{10}\right)}$,

where $V_{\max , i}$ and $V_{\max , i}(\Delta T)$ are the reference and temperature-dependent maximum depolymerisation rate of the model $i=$ (FWD, REV, OPT, see Table 3). Similarly, the decomposition rate $k$ is modified by the $Q_{10}$ function in the FOD model.
Further, we also parameterise CUE as a linear function of the temperature change, following Allison et al. (2010) and German et al. (2012):

$\varepsilon(\Delta T)=\varepsilon_{0}+\Delta T \cdot \varepsilon_{\text {slope }}$,

where $\varepsilon_{0}$ is the CUE at reference temperature and $\varepsilon_{\text {slope }}$ is the change in CUE per ${ }^{\circ} \mathrm{C}$ temperature $(\Delta T)$ change. Finally, in the models where we partition growth and maintenance respiration, we formulate maintenance respiration as a $Q_{10}$ function of temperature:

$\lambda_{\mathrm{r}}(\Delta T)=\lambda_{\mathrm{r}, 0} \cdot Q_{10}^{\left(\frac{\Delta T}{10}\right)}$,

where $\lambda_{\mathrm{r}, 0}$ and $\lambda_{\mathrm{r}}(\Delta T)$ are maintenance respiration rate at reference and elevated temperature. Growth respiration is typically much less sensitive to warming than maintenance respiration (Frantz et al., 2004), and we therefore do not consider a temperature dependence of this particular respiration term. 
In our simplified model we further neglect the weaker temperature dependence of the half-saturation constants (see Davidson et al., 2012; German et al., 2012; Stone et al., 2012) and also do not consider changes in the cost of enzyme production as temperature increases in the case of the OPT model.

\subsection{Parameterisation and implementation}

All models are implemented in STELLA, version 10.0.3. To enable comparison among the models, we adjust parameters in the following way: the models have the same initial soil organic carbon and the same initial microbial biomass. Both CUE $(\varepsilon)$ and its temperature dependence $\left(\varepsilon_{\text {slope }}\right)$ are the same across models. Further, the temperature sensitivities of $V_{\max }$ are identical across models so that we obtain the same increase in depolymerisation in the first time step after the temperature perturbation. This kind of parameterisation is motivated by the fact that many of these parameters are largely unknown, but it will provide us with the possibility of comparing the functional response to long-term warming across these models.

We use parameters as reported in German et al. (2012), with a few modifications. Here, we report $V_{\text {max,FWD }}$ and $K_{\mathrm{m}}$ by considering $15^{\circ} \mathrm{C}$ as our reference temperature and by incorporating German et al. (2012) tuning coefficients $\left(a_{K}, a_{V}\right)$ directly into these two parameters (Table 3). In other words, $V_{\text {max,FWD }}$ and $K_{\mathrm{m}}$ are the product of the reference values in German et al. (2012), their adjustment to our reference temperature, $15^{\circ} \mathrm{C}$, and the tuning parameters of German et al. (2012). Further, we have converted the exponential temperature sensitivity of $V_{\max , F W D}$ into a $Q_{10}$ term.

To allow a diminishing return mechanism, we assumed that most of the enzyme decay or loss in a scavenging model is attributed to microbial consumption instead of denaturation. Alternatively, under conditions of limited enzymesubstrate reaction sites, we assumed that there is an excess of free enzymes, and therefore, enzyme concentrations are higher than their corresponding half-saturation concentrations. Overall, these assumptions would suggest a $K_{\mathrm{e}}$ that is smaller than $M\left(K_{\mathrm{e}}<M\right)$. Here, we chose $K_{\mathrm{e}}$ considerably but not diminishingly smaller than $M$ equilibrated at reference temperature $\left(K_{\mathrm{e}}=0.37\right.$ times equilibrated $\left.M\right)$. Note that the half-saturation constant in the REV model has a different unit $\left(\mathrm{mg} \mathrm{M} \mathrm{cm}{ }^{-3}\right)$ than in the FWD model $\left(\mathrm{mg} \mathrm{S} \mathrm{cm}{ }^{-3}\right.$ ) (see Appendix A for the FWD model and Appendix $\mathrm{B}$ for the REV model). This leaves the determination of $V_{\text {max }}$ REV, which is tuned here such that the REV model yields equivalent equilibrium values of $S$ at the reference temperature to the FWD model.

In the OPT model, we adjust $V_{\max }$, OPT (in the same manner as in the REV model) such that the system again yields equilibrium values for $S$ at the reference temperature $\left(15^{\circ} \mathrm{C}\right)$ and the same initial response to warming as in the other models. In the OPT model, we have to work with two additional parameters, namely the cost of enzyme production $(c)$ and the term that contains the affinity of enzymes for the substrate $\left(K_{\mathrm{p}}\right)$. We chose to have the OPT models comparable to others if the cost $(c)$ is zero. Higher costs $(c>0)$, therefore, will yield different equilibrium results of $S$ and a different response to warming, depending on the cost of enzyme production.

Both the half-saturation constant (affinity parameter, $K_{\mathrm{p}}$ ) and the cost per enzyme produced are parameters that are hard to come by. Instead, the relationship between enzyme production cost and overall depolymerisation allows us to quantify the product of $K_{\mathrm{p}}$ and $c$ (see Eq. 8 in the main text). We define a fractional expense $\mu$ that quantifies the enzyme expenditures relative to overall depolymerisation at the reference temperature steady state, and at zero cost $(\mu=$ $\left.\left.\frac{P c}{D}\right|_{\text {Eq. }, \Delta T=0}\right)$. We chose $\mu$ to be 0,10 , and $50 \%$ of the depolymerisation rate at the reference temperature and at steady state. Based on the relationship given in Eq. (8) we then obtain an expression for the combined cost $(c)$ and the halfsaturation constant $\left(K_{\mathrm{p}}\right)$ without having to specify the value of the individual parameters (see also the variable $Y$ in Table 2):

$K_{\mathrm{p}} \cdot c=\mu^{2} \cdot D_{\text {Eq. }, \Delta T=0}$,

where $D_{\text {Eq., } \Delta T=0}$ is the rate of depolymerisation at zero enzyme cost and reference temperature.

When separating growth and maintenance respiration, we sought to equalise steady-state CUE, $M$, and $S$ by tuning $g$ and $\lambda_{\mathrm{r}}$. We first parameterised maintenance respiration, where, the coefficient for maintenance respiration is scaled to microbial turnover (Van Bodegom, 2007). The partitioning between growth and maintenance respiration is motivated by vegetation models. Lund-Potsdam-Jena (LPJ; Sitch et al., 2003) and the Ecosystem Demography Model (ED; Moorcroft et al., 2001) have a growth respiration factor of onethird of the carbon allocated to growth. We then constrain the overall respiration by the CUE in German et al. (2012) and obtain a maintenance respiration rate by difference. This yields a maintenance respiration rate that is close to the microbial death rate such that

$\lambda_{\mathrm{r}, 0}=1.25 \cdot \lambda_{\mathrm{d}}$

The second parameter, $g$ is adjusted such that the CUE at the steady state and reference temperature remains the same. This constrains $g$ to

$g=\frac{\lambda_{\mathrm{d}}-\varepsilon_{0} \cdot\left(\lambda_{\mathrm{d}}+\lambda_{\mathrm{r}, 0}\right)}{\lambda_{\mathrm{d}}-\varepsilon_{0} \cdot \lambda_{\mathrm{r}, 0}}$.

To obtain the same equilibrium values of CUE at $20^{\circ} \mathrm{C}$ as in the base models, we adjust $Q_{10, \lambda_{\mathrm{r}}}$ such that models with maintenance respiration have the same CUE as the base models.

Finally, in the FOD model, the traditional decomposition model, we adjust the parameters $k$ and $\varepsilon_{0}$ to obtain the same 
$S$ and CUE as in all other models at $15^{\circ} \mathrm{C}$, and we employ a $Q_{10, k}$ value identical to the $Q_{10}$ values of $V_{\max }$ in the other models. We keep the decreasing CUE - a feature not typically set up in traditional models.

All parameter values are given in Table 3 .

\section{Results}

\subsection{Base model simulations}

Figure 2 shows the transient response of the different models (FWD, REV, OPT, and FOD) to a temperature step from 15 to $20^{\circ} \mathrm{C}$. Recall that the perturbation occurs after all models were equilibrated at $15^{\circ} \mathrm{C}$ and are forced through the same initial values of $M, S$, and CUE by way of parameter adjustments. Also, by identical $Q_{10}$ of $V_{\max }$ and CUE, the initial response to warming is equal across the models.

In all models, warming leads to a decline in soil organic matter and microbial biomass (Fig. 2). In this initial comparison, we assume that there is no cost associated with microbial enzyme production. Across all the models, microbial biomass first increases because of higher depolymerisation. Increased depolymerisation causes soil organic matter to decrease. In the longer term, $M$ decreases as rates of depolymerisation decline due to a reduction in $S$ and due to lower CUE. We note that $M$ becomes identical across all models in the long term when soil organic carbon has equilibrated with microbial processing at higher temperature (see also Table 2).

The FWD model shows the oscillations in $M$ and $S$, as noted earlier (Wang et al., 2014). The warming triggers an increase in depolymerisation, which in turn feeds microbial biomass, causing an even higher rate of depolymerisation. This positive feedback experiences a break only when the substrate $(S)$ is sufficiently depleted, such that microbial biomass begins to decline. Thereafter, the positive feedback takes over again, the decreasing microbial biomass spirals down along with depolymerisation until microbial biomass is low enough for soil organic matter to recover. The amplitude of the oscillations dampens over time (Fig. 2). Rates of respiration oscillate along with microbial biomass, before settling at the initial rate in the long term (after ca. 200 years).

The transient dynamics in the REV model with a diminishing return as enzyme (or microbial) concentration increases are smoother compared to the FWD model (Fig. 2). The mechanism of allowing a finite site for enzyme-substrate reaction or microbial scavenging for enzymes curbs the growth of microbial biomass. Warming still leads to an initial increase in microbial biomass, owing to the fact that the gains of depolymerisation outweigh losses from increased respiration (i.e. decreased CUE). As soil organic matter depletes, microbial biomass is reduced, ultimately below the initial levels.

The OPT model considers the metabolic cost of enzyme production and allows optimisation of microbial growth. In
Fig. 2, the temporal evolution of $M, S$, respiration, and CUE is shown for a set-up without any costs associated with enzyme production. Among the three microbial models presented here (FWD, REV, OPT), the OPT model shows the strongest soil organic matter decrease in response to warming. The response in the OPT model is also almost identical with the traditional FOD model. The transient response also shows a smaller initial growth of $M$ in the OPT vs. the REV model.

\subsection{Analytical steady-state solutions}

The analysis of equilibria helps to understand the model behaviour. We first address the "long timescale" in Table 2 where we solve for the steady state of the entire system (i.e. $\frac{\mathrm{d} M}{\mathrm{~d} t}=0$ and $\left.\frac{\mathrm{d} S}{\mathrm{~d} t}=0\right)$. In the long term, the steady-state microbial biomass is identical in the FWD and the REV model and depends on the input of fresh organic matter, the microbial CUE, and microbial turnover (Table 2, rightmost column). The same microbial biomass is also realised in the OPT model under zero cost $(\mu=0)$ (see Eq. 16 and Table 2, rightmost column). In contrast, the analytical steady-state solutions of $S$ are different among the models: for the REV and the OPT model, the input of fresh litter is a determining variable for the steady state but not for the FWD model. In the OPT model the resulting equilibria of $S$ and $M$ end up being complex expressions, and we did not calculate the long-term equilibria of $M$ but expressed them simply as a function of soil organic matter. Further, the steady states of $S$ are the same in the traditional first-order model (FOD) and the OPT model with zero cost. As expected, the effect of enzyme production cost has a negative impact on microbial biomass.

The analysis of the short-term quasi-steady state of the microbial biomass $\left(\frac{\mathrm{d} M}{\mathrm{~d} t}=0\right)$ is useful to understand the trajectory of the coupled $S-M$ system. Typically, microbial turnover is much faster than the turnover of bulk soil organic matter (Stark and Hart, 1997; Schmidt et al., 2007). Thus, we would expect that microbial biomass is approaching a quasisteady state given any level of $S$.

In the FWD model, we find that the quasi-steady state for $M$ requires a perfect balance of parameters that govern growth and death rates (Table 2, second column). This has been referred to as knife-edge equilibrium (Schimel and Weintraub, 2003). The absence of such a balance leads to either an exponential growth (if positive balance) or decay (if balance is negative) of the microbial biomass in the short term, where changes in $S$ are small. It becomes clear that the soil organic matter pool must respond on a similar timescale to microbes in order to maintain microbial biomass within realistic boundaries. In the REV and the OPT models, the short-term equilibria are a function of soil organic matter (Table 2, second column). In the REV and the OPT model, $\bar{M}$ is strongly determined by the rate of depolymerisation at a given $S$, the CUE, and the microbial death rate. A weaker 


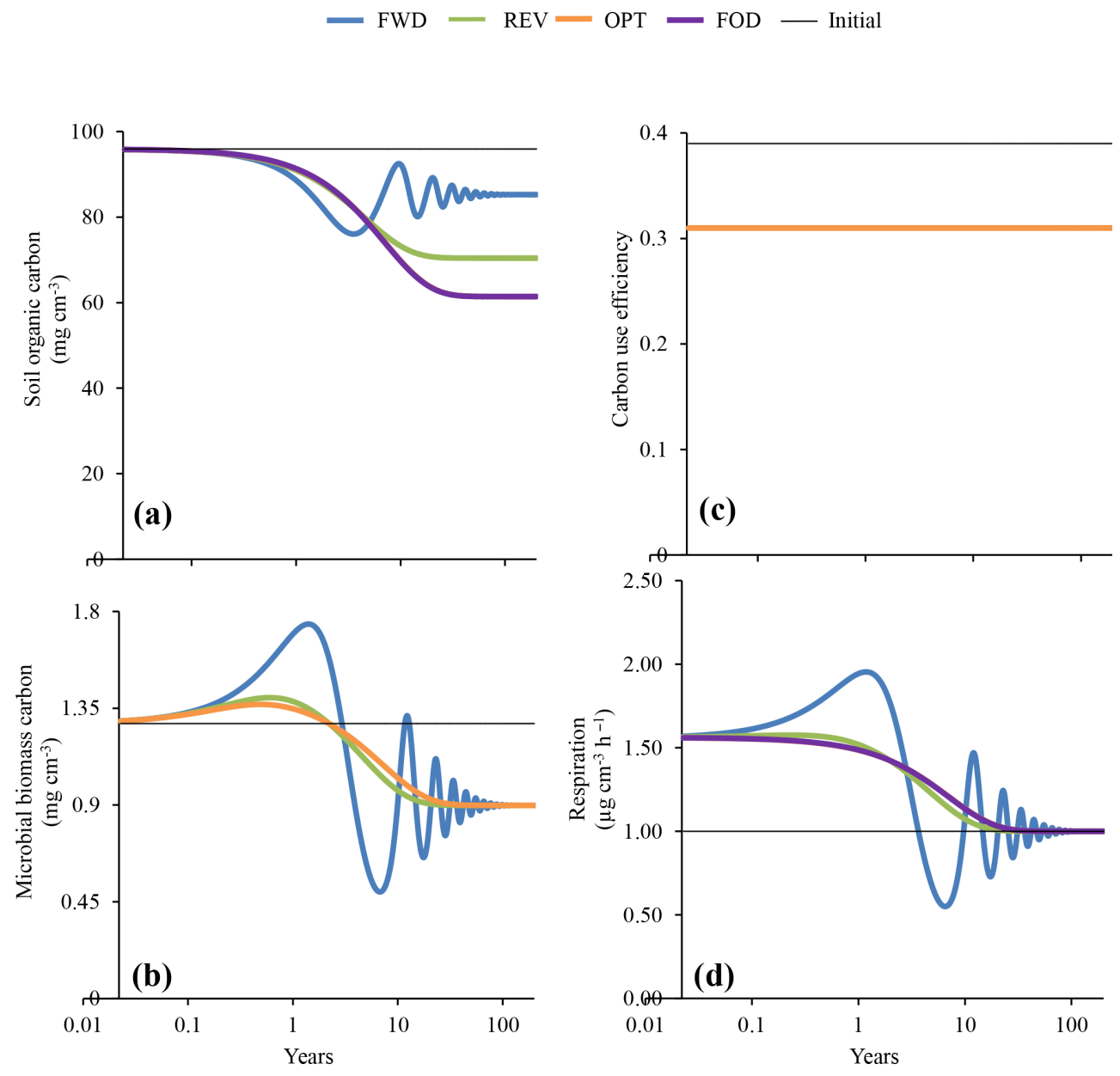

Figure 2. Responses of (a) soil organic carbon, (b) microbial biomass carbon, (c) CUE, and (d) respiration to a $5^{\circ} \mathrm{C}$ warming in the base models (FWD vs. REV and OPT, Fig. 1a). The black line represents initial values, which are model equilibria at $15^{\circ} \mathrm{C}$. We chose logarithmic axes for time to better highlight the differences in short-term responses. We note that the differences in simulated soil organic carbon and respiration for the OPT and the FOD are almost equal and therefore not discernible. Also, values of CUE at warmed temperature are identical in all models, and therefore, the orange line is superimposed on blue and green lines. In the OPT model, simulations are carried out at zero enzyme production cost, i.e. $\mu^{2}=K p \cdot c=0$ ).

affinity for the substrate (larger half-saturation constant) and higher enzyme production cost act to reduce $\bar{M}$ in these models.

\subsection{Quasi-steady state (QSS) of microbial biomass}

Given the quasi-equilibrium biomass and the resulting decomposition at quasi-steady state, we set up a second line of modelling experiments, where depolymerisation rates, as well as microbial respiration and death, are calculated based on microbial biomass at quasi-steady state (QSS microbe; Table 2, second and third columns; see also Sect. 2.1.2 in the "Materials and methods" section). Compared to the base models, the QSS microbe models yield very similar results for $S$ and respiration, but they do not reproduce the early adjustment of the microbial biomass to the temperature step (Fig. 3). Instead of a slow adjustment to the sudden warm- ing, $\bar{M}$ increases with the instantaneous increase in depolymerisation. However, over a timescale of $<1$ year, $\bar{M}$ and $R$ converge to the values of the base models in the REV and the OPT models, and therefore, the quasi-steady state appears to be an acceptable assumption over medium to long timescales. Our results further show that the depolymerisation in the OPT model at quasi-equilibrium and at marginal enzyme production cost $(\mu \rightarrow 0)$ yields a depolymerisation formulation that is functionally the same as a first-order decomposition model. Depolymerisation in the OPT model becomes $V_{\max } \cdot S$ in the absence of enzyme production cost (see Table 2), and therefore, the entire dynamics have the familiar first-order characteristics (compare Eqs. 9 and 11). 

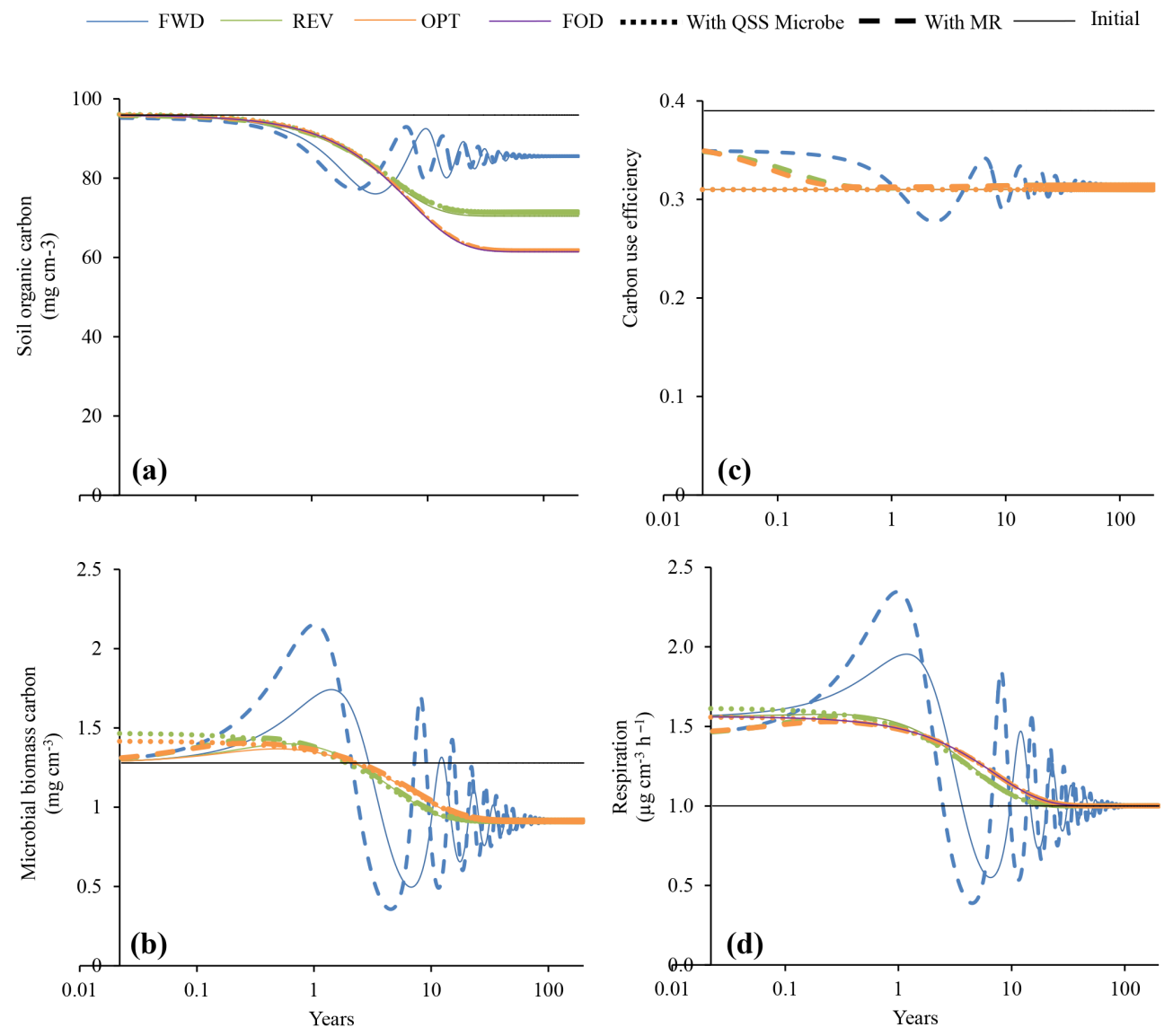

Figure 3. Responses of (a) soil organic carbon, (b) microbial biomass carbon, (c) CUE, and (d) respiration to a $5^{\circ} \mathrm{C}$ warming for all models if microbial biomass is assumed to be at quasi-steady state (QSS, dotted lines) and if separation of maintenance and growth respiration are considered (dashed lines). Coloured thin lines represent base models. The black thin line represents initial values, equilibrated at $15^{\circ} \mathrm{C}$. Dashed lines (growth and maintenance) and dotted lines (quasi-steady state) represent modifications for REV and OPT models, respectively. In the OPT model, simulations are carried out at zero enzyme production cost (i.e. $\mu^{2}=k_{\mathrm{p}} \cdot c=0$ ).

\subsection{Partitioning between maintenance and growth respiration}

In the third modification of our base models, we partition respiration in our models into a temperature-independent growth respiration and a temperature- (and biomass)dependent maintenance respiration. This affects the transient pattern of the FWD in that it increases the feedback between microbes and substrate (evidenced by higher amplitudes in $M, S$, and respiration; Fig. 3). This is because part of respiration is now tied to microbial biomass, which lags behind depolymerisation. CUE initially decreases less than in the base model, as maintenance respiration lags behind the growing microbial biomass. The maintenance term also introduces a mild oscillation into CUE, as microbial biomass waxes and wanes. Interestingly, the inclusion of maintenance respiration increases oscillation frequency and amplitude of $S$ and $M$. In the REV and the OPT model, microbial biomass is slightly higher and respiration is slightly below the values of the base models shortly after the step increase; however, this difference diminishes over time (Fig. 3). The nuanced consideration of microbial respiration causes CUE to decline in two stages. The initial drop occurs via the immediate increase in maintenance respiration. This drop is followed by further changes in CUE as $M$ oscillates (FWD model) or as $M$ net growth is diminishing (REV and OPT). Similar to microbial biomass, differences disappear within $<1$ year after the step warming. We note that in our modelling set-up, we adjusted the temperature sensitivity of the maintenance respiration such that CUE is the same at the reference $\left(15^{\circ} \mathrm{C}\right)$ and the elevated $\left(20^{\circ} \mathrm{C}\right)$ temperature.

\subsection{Enzyme production expenditures}

Finally, we analyse in the OPT model how levels of costs associated with enzyme production affect soil carbon storage and response to temperature (Fig. 4). Because of largely unknown parameters, we express enzyme expenditures as the fraction of respiratory carbon for enzyme production per unit carbon depolymerised at the reference state (see Eqs. 8 and 

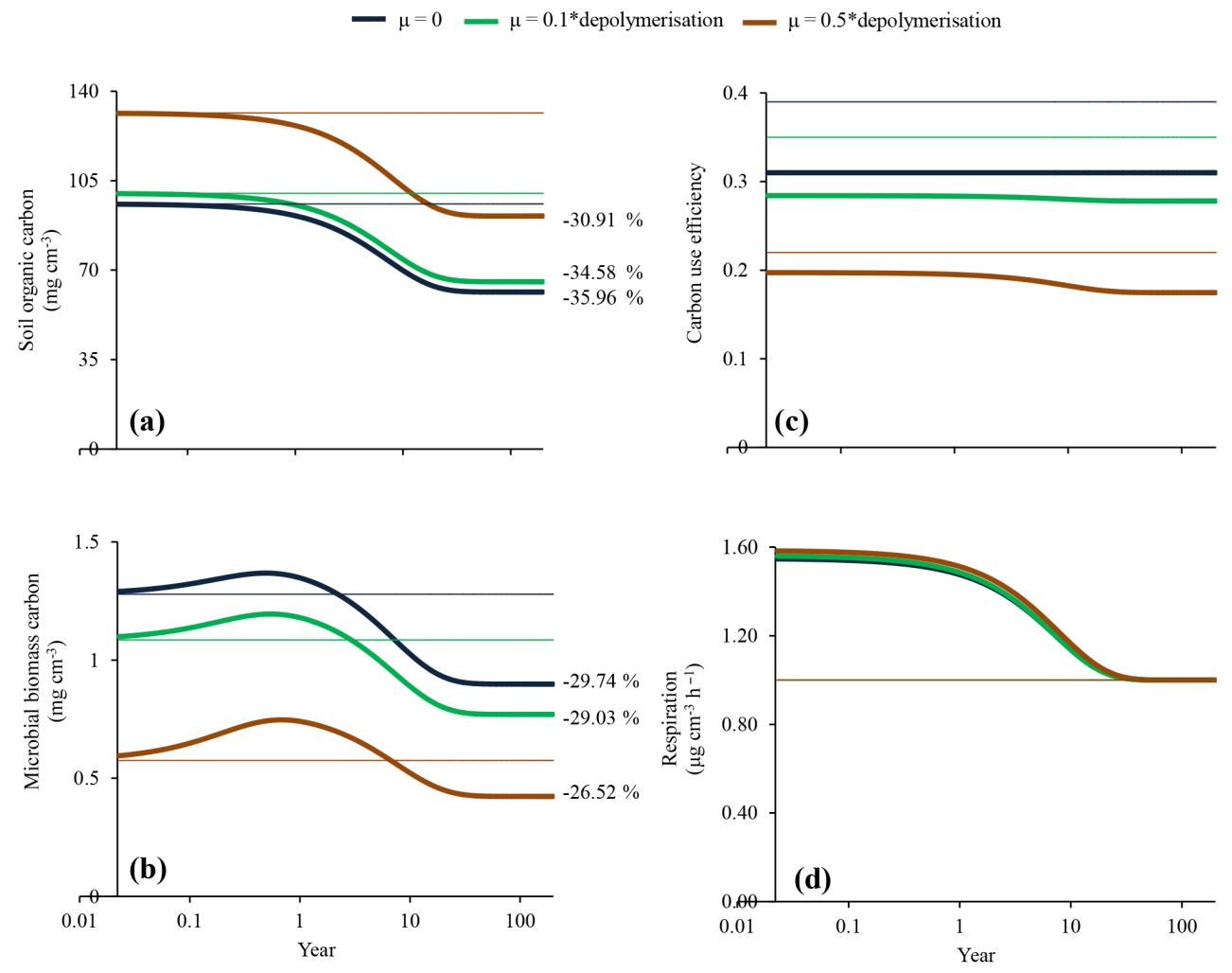

Figure 4. Long-term responses of optimised enzyme production (OPT) model to a $5{ }^{\circ} \mathrm{C}$ warming in (a) soil organic carbon, (b) microbial biomass carbon, (c) CUE, and (d) respiration operating at different relative enzyme production costs ( $\mu$, see Eq. 16). Thick lines represent warming response and thin lines represent corresponding equilibrium at the reference temperature.

16). We tested three levels of enzyme production cost: 0,10 , and $50 \%$ of equilibrium depolymerisation at our reference condition (i.e. $15^{\circ} \mathrm{C}$ ). As expected, increasing enzyme production cost reduced the rate of depolymerisation, and $S$ is therefore maintained at a higher level. The increasing costs also resulted in a smaller relative decline in $S$ in response to warming, whereas the absolute loss is larger, as indicated by the consistently higher rates of respiration. Similarly, the response of CUE to warming is smaller and the decline in $M$ is less pronounced if enzyme production costs are considered.

\section{Discussion}

Recently developed microbial decomposition models (Schimel and Weintraub, 2003; Allison et al., 2010; German et al., 2012) highlight the importance of microbial processes and microbial physiology during decomposition. Their application specifically highlights the role of extracellular enzymes during decomposition and how these constraints will further affect the release of soil organic matter as a consequence of warming. While microbial decomposition models are able to improve prediction of organic carbon stock globally and can successfully recreate litter decomposition dynamics, the long-term trajectory of a warming response needs further evaluation (Wang et al., 2014; Hararuk et al., 2015). In particular, a positive feedback between depolymerisation and microbes can only be curbed via the longer-term adjustment of soil organic matter and therefore lead to oscillation in both microbial biomass and soil organic matter (Wang et al., 2014). The oscillation is the consequence of a positive feedback between depolymerisation and microbial growth caused by a knife's edge or unstable equilibrium in the short term (unstable QSS for microbes; Schimel and Weintraub, 2003). A break in this feedback and stabilisation only occurs via the slow changing soil organic matter pool. We note that some attenuation of the oscillation may occur via direct input into a DOC pool that does not require depolymerisation (Allison et al., 2010), a feature not considered here.

The display of oscillation in the FWD model has been a point of critique as it has not been observed in laboratory and field incubation studies (Wang et al., 2014). Here, we introduce mechanisms that curb the positive feedback between substrate and microbial biomass. We portray two scenarios, where each increment in microbial biomass or enzyme concentration yields a smaller increase in depolymerisation than the previous increment (i.e. diminishing return). The scenarios we worked out are (1) microbial biomass feeds on ac- 
tive extracellular enzymes and (2) limited sites for substrateenzyme reactions (see Appendix B). We derived the forms of depolymerisation from the original Michaelis-Menten kinetics and the resulting formulations presented in the "Materials and methods" section are simplified and more illustrative versions of more complex functions. The simplified formulation of depolymerisation and microbial consumption we obtained has been dubbed a reverse Michaelis-Menten formulation (Schimel and Weintraub, 2003) because microbial biomass (or enzyme concentration) instead of the substrate concentration now occurs in the denominator of the depolymerisation term, invoking the diminishing return. Wang and Post (2013) arrived at a reverse Michaelis-Menten depolymerisation function if enzymes only adsorbed to a fraction of binding sites because of complex substrates. Transitions between FWD and REV model behaviour have also been detailed in the more complex Equilibrium Chemistry Approximation model that also included sorption of enzymes and substrates to mineral surfaces (Tang and Riley, 2015; Tang, 2015). Our analysis shows that the positive feedback between decomposition and microbial growth is removed, as our REV model now has a stable short-term QSS.

Limited sites may play a role if the substrate has a high volume-to-surface ratio, or if the substrate is associated with minerals (Davidson and Janssens, 2006; Gillabel et al., 2010; Conant et al., 2011; Davidson et al., 2012, 2014; Cotrufo et al., 2013; Wagai et al., 2013; Benbi et al., 2014; Wieder et al., 2014a; Tang and Riley, 2015). Our implementation of limited substrate causes a surplus of free enzymes that compete for binding to substrates, similar to the Langmuir adsorption isotherm theory (Vetter et al., 1998; Schimel and Weintraub, 2003; Wang and Post, 2013; and see Appendix B, "Model with limited available substrate"), leading to diminishing depolymerisation returns and a REV model formulation. Effects of microbial scavenging for enzymes cause a diminishing return because more microbial biomass will lead to an increased probability of enzymes being consumed before they interact with soil organic matter. Other mechanisms of diminishing return as enzymes increase may be the stabilisation of enzymes into an organic-matter-humate complex (Allison, 2006) or sorption to minerals, soil organic matter, or microbes (Tang and Riley, 2015). Diminishing returns also occur with rate-yield trade-offs (Allison, 2014).

Many microbial decomposition models work under the assumption that enzyme production is proportional to microbial biomass; however, it is also conceivable that microbes are adjusting production to maximise return or growth (Cooney, 2009; Merchant and Helmann, 2012; Tang and Riley, 2015). In our OPT model, we relax the proportionality of microbial enzyme production and microbial biomass and instead allow a best possible return given the cost of enzyme synthesis. While the exact cost of enzyme production is not known, we fixed parameters (the product of $K_{\mathrm{p}}$ and $c$ ) that relate to the fractional expense of carbon depolymerised upon initialisation (i.e. at steady state and reference temperature;
Eqs. 8 and 16). Importantly, enzyme production optimisation is not possible for some of the models presented here. Higher enzyme production would always lead to further microbial growth in the FWD model, and the highest yield would occur with infinite enzyme production. Similarly, in the case of microbial scavenging for enzymes, additional investments into enzymes always increase depolymerisation.

The response to temperature in our OPT model closely resembles the traditional first-order decay model (FOD). In the limit of enzyme production cost approaching zero, depolymerisation occurs at the maximum rate $\left(V_{\max } \cdot S\right)$, essentially turning the OPT model into a first-order model (Fig. 2). In the OPT model, reductions in depolymerisation via $K_{\mathrm{p}}$ are alleviated when enzyme synthesis is inexpensive, where the reduction in the maximum depolymerisation rate becomes a function of the product of $K_{\mathrm{p}} \cdot c$ (Eq. 7 and Table 2). The results of the OPT model also show the effects on assumptions regarding microbial enzyme production rates. In many microbial models, enzyme production is scaled to microbial biomass. Lifting the tight coupling between microbial biomass and enzyme production leads to a more dynamic enzyme concentration and ultimately affects the temperature sensitivity of decomposition. Thus, the cost and trade-offs associated with microbial enzyme production are potential important areas to better quantify the long-term response of soil carbon storage to climate change.

The response of decomposition to warming can be viewed as a response occurring on multiple timescales. For example, while enzyme activity likely produces an immediate response, microbial respiration responses may also be triggered quickly, although longer-term acclimation may occur (Frey et al., 2013). It may take longer for microbial biomass to respond to temperature changes (weeks to months). Finally, because the rate of decomposition is slow compared to the overall abundance of soil organic matter, discernible changes in this pool occur on timescales of months to years. Based on the distinct rates of adjustments, timescales can in principle - be separated by assuming a quasi-steady state of pools that turn over fast.

The assumption that both enzyme concentrations and DOC (i.e. the depolymerisation products) are at quasi-steady state cuts across all models presented here (FWD, REV, and OPT; see Appendix A). When we extend our assumption of steady state to the microbial timescale (quasi-steady state of microbial biomass), we find that for both the REV and the OPT model, the short-term response of microbial biomass and respiration is influenced by the adjustment of microbial dynamics to the warmer temperature (Fig. 3). Because microbial biomass jumps immediately to a higher level after the temperature increase in our QSS assumption, depolymerisation, and thus respiration, are affected. However, the QSS assumption affects the trajectory of the soil carbon pool only minimally. On timescales that allow microbes to turn over a couple of times (several months), the quasi-steady state poses a suitable approximation to represent respiration and micro- 
bial biomass, even after a sharp perturbation in the form of a step change. In the QSS assumption, depolymerisation becomes independent of the microbial biomass (but is still dependent on a combination of microbial parameters; see Table 2).

The introduction of QSS microbial biomass allows addressing and comparing the long-term responses of the different models to warming. In particular, the comparison of the QSS-derived depolymerisation of the FOD with the REV and the OPT directly show the effect of how enzymesubstrate affinity and enzyme production costs dampen the rate of depolymerisation and its response to temperature. In other words, the long-term response of the FOD is equivalent to the long-term response of our OPT or REV model, when (1) $K_{\mathrm{e}}$ is low (high enzyme production, high enzymesubstrate affinity, and low enzyme turnover) and/or (2) costs of enzyme production are low, and (3) and CUE (the fraction of the organic matter pool that is depolymerised but not respired and instead cycled back into soil) is also temperature dependent in the FOD, a feature typically not included in traditional decomposition models.

CUE ultimately is the result of different microbial respiration terms. Here, we consider three processes that may affect microbial respiration under a warming scenario. We first consider a partitioning into growth and maintenance respiration across our three models. Growth respiration is simply assumed to be a proportion of carbon allocated to microbial growth. In contrast, maintenance respiration scales to microbial biomass in our models, where the proportionality factor increases with temperature. This partitioning is motivated by formulations of plant respiration in terrestrial biosphere models. We find that this separation affects the short-term responses of respiration because microbial biomass lags behind the increase in depolymerisation. The temperature response of CUE is thus delayed. The partitioning of the respiration terms also has a particular impact on the transient dynamics of the FWD model, in that the lag in maintenance respiration amplifies the oscillation (Fig. 3). However, in the REV and the OPT model, effects of separation are only discernible on the microbial timescale, before microbial biomass is approaching quasi-steady-state values.

In the OPT model, we introduce an additional respiration term, namely the cost of enzyme production. In this model, we allow microbes to adjust enzyme production in order to optimise growth. It is interesting that increasing costs lead to a smaller immediate response in respiration and more resilient soil organic matter pool in the long term, when subject to warming (Fig. 4). The early respiration response in the OPT model is a product both of higher rates of depolymerisation (increased $V_{\max }$ ) and of a higher rate of enzyme production. However, the enhancement relative to the rates at the reference temperature becomes smaller with higher enzyme production cost. In the long term, the decrease in soil organic matter is reduced when enzyme production costs are considered. This reduction is accompanied by a smaller reduction in CUE under higher enzyme production, even though there is a subsequent CUE reduction occurring as $S$ declines. The changing yield trade-off overall acts to buffer respiration increases that could be expected from physiological responses alone $\left(V_{\max }\right)$, although the effects are smaller and may be well within the uncertainty of the temperature response of any parameters considered here. We note that enzyme expenditure relative to depolymerisation is a function of the product of $K_{\mathrm{p}}$ and $c$.

We acknowledge that we used a simplified set-up of our model suite. For example, we assumed that depolymerised carbon in soil solution (DOC) is always in steady state with the microbial biomass (see also German et al., 2012, and Moorhead et al., 2012). This simplification can be justified with fast and efficient scavenging of microbes and, thus, fast turnover of the DOC pool. Further sensitivity analysis may shed light on the dynamics across the full parameter space, while using the simplified linear terms (Appendices B and C; Tang, 2015), particularly also because many of the parameters are difficult to estimate. Furthermore, we did not include nutrient requirements of microbes where considering the stoichiometric requirements can change the allocation of resources to optimise enzyme synthesis. Finally, our model does not include interaction that may occur with adsorption to mineral surfaces, which may occur with the substrate, the enzymes and microbial biomass, and which has important short- and long-term consequences for to temperature fluctuations and changes (Wieder et al., 2014a; Tang and Riley, 2015). Nevertheless, our suite of models shows the importance of formulating the depolymerisation step in mathematical models when evaluating the response of decomposition under warming.

Microbial models are considered to be more realistic because of the mechanistic representation of the decomposition steps, yet the oscillatory behaviour has been viewed as an unrealistic response to perturbation (Wang et al., 2014). Perhaps on a more fundamental level, first-order decomposition models inherently assume substrate limitation while the FWD model incorporates enzyme availability (and enzyme production) as the limiting step during decomposition. Here, we show that first-order models can be viewed as a special case of a microbial model that considers a limitation other than enzyme availability (i.e. diminishing returns) and low values of the half-saturation constant (REV model), or alternatively, a decoupling of microbial enzyme production from microbial biomass (OPT model). While moving from the FWD to the REV model (diminishing return) introduced a form of substrate limitation, optimising enzyme production can be viewed as a further alleviation (or removal under marginal production cost) of enzyme limitation. Since the response to warming is vastly different across our suite of models, our results suggest that the degree of enzyme limitation and the microbial response to enzyme limitation are potential areas that could help constrain the quantification of the long-term response of soil organic matter to warming. 


\section{Conclusions}

Our findings suggest that different formulations of microbial substrate acquisition will have a significant impact on the short- vs. long-term consequences of warming. Here, we present simple, yet feasible, mechanisms of microbial dynamics. We show that substrate limitation in the form of decreasing marginal return can create a break in the positive feedback between microbial biomass and depolymerisation, turning a forward Michaelis-Menten model into a reverse model. We further separate out three types of respiration that have possible consequences for the temporal trend of CUE in response to warming. Although such separation is more mechanistic, it remains an open question whether the addition of extra parameters is justified at this point, given the uncertainty in models, and because much of the effects of this separation diminishes on timescales longer than the microbial lifespan. Finally, among our suite of models, our OPT model most closely resembles the traditional first-order decomposition model. In our modelling framework, a firstorder model is a special case of a microbial decomposition model where (1) mechanisms of diminishing returns break the feedback between substrate and microbes, (2) the proportionality of enzyme production and microbial biomass is relaxed and adjusted to yield optimum return of enzyme investments, (3) costs associated with enzyme synthesis are small (and/or enzyme-substrate affinity is high), and (4) microbes turn over relatively fast compared to soil organic matter. Our results thus suggest that a better grasp of the limiting steps of decomposition and mechanisms of microbial enzyme production will help to constrain the long-term response to warming. 
Appendix A: Michaelis-Menten kinetics with enzyme denaturation

The dynamics of the enzyme-substrate complex are

$$
\begin{aligned}
& \frac{\mathrm{d}[E]}{\mathrm{d} t}=P-K_{S}[S][E]-\lambda_{E 1} \cdot[E]+K_{\mathrm{r}}+K([\mathrm{ES}], \\
& \frac{\mathrm{d}[\mathrm{ES}]}{\mathrm{d} t}=-\left(K_{\mathrm{cat}}+K_{\mathrm{r}}+\lambda_{E 2}\right)[\mathrm{ES}]+K_{S}[S][E],
\end{aligned}
$$

where $P$ is the microbial production of new enzymes, $[S]$ is the concentration of the substrate, $[E]$ is the concentration of enzymes, [ES] is the substrate-enzyme complex, and $K_{\mathrm{S}}, K_{\text {cat }}$, and $K_{\mathrm{r}}$ are reaction constants that denote substrateenzyme binding, actual depolymerisation rate, and the reversibility of the enzyme-binding process. $\lambda_{E 1}$ and $\lambda_{E 2}$ are enzyme decay parameters that lead to enzyme denaturation or render enzymes inactive in the free enzyme pool or in the enzyme-substrate complex, respectively. In the FWD and REV model, $P$ is proportional to microbial biomass. The Michaelis-Menten approximation for depolymerisation assumes that the system is in quasi-steady state in which the tendency $\frac{\mathrm{d}[\mathrm{ES}]}{\mathrm{d} t}$ and $\frac{\mathrm{d}[E]}{\mathrm{d} t}$ is zero. This also implies that the tendency of the total enzyme concentration $\frac{\mathrm{d}\left[\mathrm{E}_{\mathrm{t}}\right]}{\mathrm{d} t}$ (with $\left[E_{\mathrm{t}}\right]$ $=[\mathrm{ES}]+[E])$ becomes zero.

Setting Eq. (A2) to zero, and substituting $\left[E_{\mathrm{t}}\right]=[\mathrm{ES}]+$ $[E]$, it follows that

$$
\begin{aligned}
& {[E]=\frac{\left[E_{\mathrm{t}}\right] K_{\mathrm{m}}}{\left([S]+K_{\mathrm{m}}\right)},} \\
& {[\mathrm{ES}]=\frac{\left[E_{\mathrm{t}}\right][S]}{\left([S]+K_{\mathrm{m}}\right)} .}
\end{aligned}
$$

And the rate of depolymerisation is

$$
D=\frac{\left[E_{\mathrm{t}}\right] \cdot V_{\max } \cdot[S]}{\left([S]+K_{\mathrm{m}}\right)},
$$

where $D$ is the familiar Michaelis-Menten equation with $K_{\mathrm{m}}=\frac{K_{\mathrm{cat}}+K_{\mathrm{r}}+\lambda_{E 2}}{K_{S}}$ and $V_{\max }$ is equivalent to $K_{\text {cat }}$.

\section{DOC and enzyme dynamics}

We assumed that DOC concentrations are in equilibrium with substrate and microbial uptake. In microbial decomposition models, the only DOC sink is microbial consumption, which by way of mass conservation, leads to microbial consumption being equivalent to the rate of depolymerisation.

Previous models (Allison et al., 2010; German et al., 2012) assumed a general decay of the total enzyme pool, where

$$
\frac{\mathrm{d}\left[E_{\mathrm{t}}\right]}{\mathrm{d} t}=P-\lambda_{E} \cdot\left[E_{\mathrm{t}}\right] .
$$

Because enzymes turn over fast, we can assume a quasisteady state of the total enzyme pool by setting Eq. (A6) to zero. We obtain

$\left[E_{\mathrm{t}}\right]=\frac{P}{\lambda_{E}}$, and depolymerisation is

$D=\frac{\frac{P}{\lambda_{E}} \cdot K_{\mathrm{cat}} \cdot[S]}{[S]+K_{\mathrm{m}}}$.

Finally, microbial decomposition models assume that enzyme production is proportional to the microbial biomass $(M): P=b \cdot M$; hence,

$D=\frac{V_{\max } \cdot M \cdot[S]}{[S]+K_{\mathrm{m}}}$,

with $V_{\max }=\frac{b \cdot K_{\text {cat }}}{\lambda_{E}}$

However, it is conceivable that the enzyme-substrate complex and free enzymes decay at different rates (see also Eqs. A1 and A2).

$\frac{\mathrm{d}\left[E_{\mathrm{t}}\right]}{\mathrm{d} t}=P-\lambda_{E 2}[\mathrm{ES}]-\lambda_{E 1}[E]$

Substituting Eqs. (A3) and (A4) for $[E]$ and [ES] and applying a quasi-steady state as before yields

$\left[E_{\mathrm{t}}\right]=\frac{P\left([S]+K_{\mathrm{E}}\right)}{\lambda_{E 1} K_{\mathrm{m}}+\lambda_{E 2}[S]}$.

And the overall depolymerisation is thus

$D=\frac{P \cdot K_{\mathrm{cat}} \cdot[S]}{\lambda_{E 1} K_{\mathrm{m}}+\lambda_{E 2}[S]}$,

which can be converted into a Michaelis-Menten form

$D=\frac{V_{\max } \cdot M \cdot[S]}{[S]+K_{S}}$,

where $V_{\max }=\frac{b \cdot K_{\text {cat }}}{\lambda_{E 2}}$ and $K_{S}=K_{\mathrm{m}} \frac{\lambda_{E 1}}{\lambda_{E 2}}$.

\section{Appendix B: Microbial consumption of enzymes}

Microbes feeding on free enzymes can be represented as

$F=\lambda_{E, M} \cdot[E] \cdot M$,

where $F$ is microbial enzyme consumption and $\lambda_{E, M}$ the feeding rate. We can then represent the decay of the free enzymes with

$[E] \cdot \lambda_{E 1}=[E]\left(\lambda_{E 1,0}+\lambda_{E, M} \cdot M\right)$,

where the total $\lambda_{E, 0}$ is the spontaneous enzyme decay rate.

Substituting the new enzyme decay formulation into the depolymerisation (Eq. A12) yields

$D=\frac{P \cdot K_{\mathrm{cat}} \cdot[S]}{\lambda_{E 2} \cdot[S]+\lambda_{E 1,0} \cdot K_{\mathrm{m}}+\lambda_{E, M} \cdot M \cdot K_{\mathrm{m}}}$.

For the REV model, we simplify Eq. (B3) and assume that enzymes associated with substrate do not undergo denaturation $\left(\lambda_{E 2}=0\right)$, which yields

$D=\frac{P \cdot K_{\mathrm{cat}} \cdot[S]}{\lambda_{E 1,0} \cdot K_{\mathrm{m}}+\lambda_{E, M} \cdot M \cdot K_{\mathrm{m}}}$. 
And, in the case where enzyme production scales to microbial biomass $(P=b \cdot M)$,

$D=\frac{M \cdot V_{\max } \cdot[S]}{K_{\mathrm{e}}+M}$,

which is again the familiar Michaelis-Menten function with $V_{\max }=\frac{b \cdot K_{\text {cat }}}{\lambda_{E, M} \cdot K_{E}}$ and $K_{\mathrm{e}}=\frac{\lambda_{E 1,0}}{\lambda_{E, M}}$.

\section{Model with limited available substrate}

Access to substrate might be finite, for example, if organic matter is associated with mineral soil or if the rate of depolymerisation is constrained by the surface area. In this case, the relationship between the total available substrate and the free sites can be calculated as

$[S]=\theta \cdot\left(\left[S_{\mathrm{f}}\right]+[\mathrm{ES}]\right)$,

where $S_{\mathrm{f}}$ is the available sites for enzyme reaction, $\theta$ a scalar relating the total amount of substrate to the total potentially free sites (e.g. a surface-to-mass conversion), and [ES] represents the sites with enzyme-substrate complexes. We note that $[S]$ in this case is not the available substrate anymore but is reduced by a fraction $\theta$.

Substituting $[E S]$ from Eq. (A4) but knowing that $[S]$ has now become $\left[S_{\mathrm{f}}\right]$, we obtain

$\left[S_{\mathrm{f}}\right]=\frac{[S]}{\theta}-\frac{\left[S_{\mathrm{f}}\right]\left[E_{\mathrm{t}}\right]}{K_{\mathrm{m}}+\left[S_{\mathrm{f}}\right]}$.

$\left[S_{\mathrm{f}}\right]$ is thus the solution of a quadratic polynomial:

$$
\begin{aligned}
{\left[S_{\mathrm{f}}\right] } & =\frac{1}{2}\left\{-\left(\left[E_{\mathrm{t}}\right]+K_{\mathrm{m}}-\frac{[S]}{\theta}\right)\right. \\
& \left. \pm \sqrt{\left(\left[E_{\mathrm{t}}\right]+K_{\mathrm{m}}-\frac{[S]}{\theta}\right)^{2}+4 \cdot \frac{[S]}{\theta} \cdot K_{\mathrm{m}}}\right\} .
\end{aligned}
$$

The scenario of a limited reaction site is relevant if $\frac{[S]}{\theta}$ is small (i.e. $\frac{[S]}{\theta} \ll\left[E_{\mathrm{t}}\right]$ ). Under this scenario, we simplify Eq. (B8) using a Taylor expansion around $\left(\frac{[S]}{\theta}=0\right)$ :

$\left[S_{\mathrm{f}}\right]=\frac{[S]}{\theta} \cdot\left(\frac{K_{E}}{\left[E_{\mathrm{t}}\right]+K_{\mathrm{m}}}\right)+O\left[\left(\frac{[S]}{\theta}\right)^{2}\right]$.

Plugging this into the depolymerisation,

$$
D=\frac{K_{\mathrm{cat}} \cdot\left[E_{\mathrm{t}}\right] \cdot \frac{[S]}{\theta}}{\left[E_{\mathrm{t}}\right]+K_{\mathrm{m}}+\frac{[S]}{\theta}} \cong \frac{K_{\mathrm{cat}} \cdot\left[E_{\mathrm{t}}\right] \cdot \frac{[S]}{\theta}}{\left[E_{\mathrm{t}}\right]+K_{\mathrm{m}}},
$$

which has a Michaelis-Menten form with a saturating enzyme concentration. This particular solution is for a small amount of binding sites, and enzymes compete for free sites.
Thus, $\left[E_{\mathrm{t}}\right] \gg \frac{[S]}{\theta}$, and it can be dropped from within the denominator. On a side note: we obtain the same expression if we approximate from Eq. (B7):

$$
\begin{aligned}
& {\left[S_{\mathrm{f}}\right]=\frac{[S]}{\theta}-\left[S_{\mathrm{f}}\right] \frac{\left[E_{\mathrm{t}}\right]}{\left[S_{\mathrm{f}}\right]+K_{\mathrm{m}}},} \\
& {\left[S_{\mathrm{f}}\right] \cong \frac{[S]}{\theta}-\frac{\left[S_{\mathrm{f}]}\left[E_{\mathrm{t}}\right]\right.}{K_{\mathrm{m}}},}
\end{aligned}
$$

which assumes very few free sites $\left(\left[S_{\mathrm{f}}\right] \gg K_{\mathrm{m}}\right)$. Therefore,

$\left[S_{\mathrm{f}}\right]=\frac{[S]}{\theta} \frac{K_{\mathrm{m}}}{\left[E_{\mathrm{t}}\right]+K_{\mathrm{m}}}$.

We can also include equations for enzyme turnover (Eq. A7) to calculate $\left[E_{\mathrm{t}}\right]$ : however, we need to substitute $[S]$ in this equation with $\left[S_{\mathrm{f}}\right]$, and thus

$$
\frac{\mathrm{d}\left[E_{\mathrm{t}}\right]}{\mathrm{d} t}=P-\frac{\lambda_{E 2} \cdot\left[E_{\mathrm{t}}\right] \cdot \frac{[S]}{\theta}}{\left[E_{\mathrm{t}}\right]+K_{\mathrm{m}}+\frac{[S]}{\theta}}-\frac{\lambda_{E 1} \cdot\left[E_{\mathrm{t}}\right] \cdot\left(\left[E_{\mathrm{t}}\right]+K_{\mathrm{m}}\right)}{\left[E_{\mathrm{t}}\right]+K_{\mathrm{m}}+\frac{[S]}{\theta}} .
$$

Maintaining $\frac{[S]}{\theta} \ll\left(\left[E_{\mathrm{t}}\right]+K_{\mathrm{m}}\right)$, we obtain

$$
\frac{\mathrm{d}\left[E_{\mathrm{t}}\right]}{\mathrm{d} t} \cong P-\frac{\lambda_{E 2} \cdot\left[E_{\mathrm{t}}\right] \cdot \frac{S}{\theta}}{\left[E_{\mathrm{t}}\right]+K_{\mathrm{m}}}-\lambda_{E 1} \cdot\left[E_{\mathrm{t}}\right] .
$$

The quasi-equilibrium solution $\left(\frac{\mathrm{d}\left[E_{\mathrm{t}}\right]}{\mathrm{d} t}=0\right)$ yields a quadratic expression for $\left[E_{\mathrm{t}}\right]$; however, we can evaluate the following scenarios:

a. Suppose $\frac{\lambda_{E 2} \cdot\left[E_{\mathrm{t}}\right] \cdot \frac{S}{\theta}}{\left[E_{\mathrm{t}}\right]+K_{\mathrm{m}}} \gg \lambda_{E 1} \cdot\left[E_{\mathrm{t}}\right]$; this assumes that enzyme decay occurs mainly when bound to the substrate.

Setting $\frac{\mathrm{d}\left[E_{\mathrm{t}}\right]}{\mathrm{d} t}=0$, we obtain

$$
\left[E_{\mathrm{t}}\right]=\frac{K_{\mathrm{m}} \cdot P}{\lambda_{E 2} \cdot \frac{S}{\theta}-P},
$$

and with $P$ proportional to microbial biomass $(M)$

$D=\frac{K_{\mathrm{cat}} \cdot P}{\lambda_{E 2}}=V_{\max } \cdot M$,

where $V_{\max }=\frac{K_{\mathrm{cat}} \cdot b}{\lambda_{E 2}}$.

In this case, depolymerisation and microbial consumption is independent of the substrate but is determined by the relative rate of catalysis and irreversible destruction of the enzyme-substrate complex.

b. Suppose $\frac{\lambda_{E 2} \cdot\left[E_{\mathrm{t}}\right] \cdot \frac{S}{\theta}}{\left[E_{\mathrm{t}}\right]+K_{\mathrm{m}}} \ll \lambda_{E 1} \cdot\left[E_{\mathrm{t}}\right]$.

This implies that enzymes mainly decay if they are not associated with the substrate and that there is an appreciable amount of free enzymes. This is realistic under substrate-limiting conditions, as there will be a sizeable 
amount of free enzymes compared to enzyme substrate complexes.

We then obtain $\left[E_{\mathrm{t}}\right]=\frac{P}{\lambda_{E 1}}$ and

$D=\frac{K_{\mathrm{cat}} \cdot P \cdot \frac{S}{\theta}}{P+\lambda_{E 1} \cdot K_{\mathrm{m}}}$.

With $P=b \cdot M$, we have

$D=\frac{M \cdot V_{\max } \cdot S}{K_{\mathrm{e}}+M}$,

where $V_{\max }=\frac{K_{\text {cat }}}{\theta}$ and $K_{\mathrm{e}}=\frac{\lambda_{E 1} \cdot K_{\mathrm{m}}}{b}$.

\section{Appendix C: Optimising depolymerisation}

Microbes may be able to optimise their growth, and thus, depolymerisation becomes a function of the metabolic costs of enzyme production. Depolymerisation based on enzyme production, assuming fixed turnover of free enzymes, yields

$D(P)=\frac{P \cdot V_{\max } \cdot[S]}{K_{\mathrm{p}}+P}$,

where $P$ is the amount of new enzyme produced, $V_{\max }$ is $\frac{K_{\text {cat }}}{\theta}$, and $K_{\mathrm{p}}=\lambda_{E 1} K_{\mathrm{m}}$, based on the model with limited available substrate.

Microbial growth $(G)$ will be

$G=(1-g) \cdot\left(D-P c-\lambda_{\mathrm{r}} \cdot M\right)$, where $g$ is the growth respiration factor, $c$ the respiratory cost per unit enzyme production, and $\lambda_{\mathrm{r}}$ the maintenance respiration factor.

Enzyme production $(P)$ can be optimised by substituting Eq. (C1) into Eq. (C2) and setting $\frac{\mathrm{d} G}{\mathrm{~d} P}=0$. This yields

$P c=-K_{\mathrm{p}} c+\sqrt{V_{\max } \cdot[S] \cdot K_{\mathrm{p}} c}$.

The proportion of carbon expended for enzyme production relative to depolymerisation is

$\frac{P c}{D}=\sqrt{\frac{K_{\mathrm{p}} c}{[S] V_{\max }}}$.

Instead of specifying $c$, we used Eq. (C4) to express overall microbial carbon expenditure for enzyme production. After assigning a value to $\mu$, we calculate c based on equilibrium $S$ at reference temperature.

In contrast, the microbial scavenging scenario does not provide an optimum enzyme production. In this case, depolymerisation is

$D=\frac{P \cdot V_{\max } \cdot[S]}{\left(K_{\mathrm{e}}+M\right) \cdot \lambda_{E}}$.

And, thus, $\frac{\mathrm{d} G}{\mathrm{~d} P}$ will yield a constant where growth scales with the rate of enzyme production. 
Acknowledgements. The authors would like to thank the Inglett and Gerber lab groups in the Soil and Water Science Department, University of Florida, for their scientific and critical discussion of model development and analysis. We also thank Will Wieder, Katerina Georgiou, and an anonymous reviewer for their insights and their constructive questions and comments. The project was partially supported by National Science Foundation (NSF) grant DEB 0841596.

Edited by: S. Zaehle

\section{References}

Allison, S. D.: Cheaters, diffusion and nutrients constrain decomposition by microbial enzymes in spatially structured environments, Ecol. Lett., 8, 626-635, doi:10.1111/j.1461-0248.2005.00756.x, 2005.

Allison, S. D.: Soil minerals and humic acids alter enzyme stability: implications for ecosystem processes, Biogeochemistry, 81, 361-373, doi:10.1007/s10533-006-9046-2, 2006.

Allison, S. D.: Modeling adaptation of carbon use efficiency in microbial communities, Frontiers in Microbiology, 5, 571, doi:10.3389/fmicb.2014.00571, 2014.

Allison, S. D., Wallenstein, M. D., and Bradford, M. A.: Soil-carbon response to warming dependent on microbial physiology, Nature Geosci., 3, 336-340, doi:10.1038/ngeo846, 2010.

Arora, V.: Modeling vegetation as a dynamic component in soilvegetation-atmosphere transfer schemes and hydrological models, Rev. Geophys., 40, 3-1-3-26, doi:10.1029/2001RG000103, 2002.

Beeftink, H. H., van der Heijden, R. T. J. M., and Heijnen, J. J.: Maintenance requirements: energy supply from simultaneous endogenous respiration and substrate consumption, FEMS Microbiol. Ecol., 6, 203-209, doi:10.1111/j.15746968.1990.tb03942.x, 1990.

Benbi, D. K., Boparai, A. K., and Brar, K.: Decomposition of particulate organic matter is more sensitive to temperature than the mineral associated organic matter, Soil Biol. Biochem., 70, 183192, doi:10.1016/j.soilbio.2013.12.032, 2014.

Cannell, M. G. R. and Thornley, J. H. M.: Modelling the components of plant respiration: some guiding principles, Ann. Bot.London, 85, 45-54, doi:10.1006/anbo.1999.0996, 2000.

Chapman, S. J. and Gray, T. R. G.: Importance of cryptic growth, yield factors and maintenance energy in models of microbial growth in soil, Soil Boil. Biochem., 18, 1-4, doi:10.1016/00380717(86)90095-7, 1986

Chertov, O. and Komarov, A.: SOMM: A model of soil organic matter dynamics, Ecol. Model., 94, 177-189, doi:10.1016/S03043800(96)00017-8, 1997.

Conant, R. T., Ryan, M. G., Ågren, G. I., Birge, H. E., Davidson, E. A., Eliasson, P. E., Evans, S. E., Frey, S. D., Giardina, C. P., and Hopkins, F. M.: Temperature and soil organic matter decomposition rates-synthesis of current knowledge and a way forward, Glob. Change Biol., 17, 3392-3404, doi:10.1111/j.13652486.2011.02496.x, 2011.

Coleman, K. and Jenkinson, D. S.: RothC-26.3 - A model for the turnover of carbon in soil, in: Evaluation of Soil Organic Matter Models Using Existing Long-Term Datasets, edited by: Powlson,
D. S., Smith, P., and Smith, J. U., Springer-Verlag, Heidelberg, 237-246, 1996.

Cooney, C. L.: Strategies for optimizing microbial growth and product formation, Foundations of biochemical engineering, Foundations of Biochemical Engineering, 207, 179-198, 2009.

Cotrufo, M. F., Wallenstein, M. D., Boot, C. M., Denef, K., and Paul, E.: The Microbial Efficiency-Matrix Stabilization (MEMS) framework integrates plant litter decomposition with soil organic matter stabilization: do labile plant inputs form stable soil organic matter?, Glob. Change Biol., 19, 988-995, doi:10.1111/gcb.12113, 2013.

Davidson, E. A. and Janssens, I. A.: Temperature sensitivity of soil carbon decomposition and feedbacks to climate change, Nature, 440, 165-173, doi:10.1038/nature04514, 2006.

Davidson, E. A., Samanta, S., Caramori, S. S., and Savage, K. E.: The Dual Arrhenius and Michaelis-Menten kinetics model for decomposition of soil organic matter at hourly to seasonal time scales, Glob. Change Biol., 18, 371-384, doi:10.1111/j.13652486.2011.02546.x, 2012.

Davidson, E. A., Savage, K. E., and Finzi, A. C.: A big-microsite framework for soil carbon modeling, Glob. Change Biol., 20, 3610-3620, doi:10.1111/gcb.12718, 2014.

Foley, J. A., Prentice, I. C., Ramankutty, N., Levis, S., Pollard, D., Sitch, S., and Haxeltine, A.: An integrated biosphere model of land surface processes, terrestrial carbon balance, and vegetation dynamics, Global Biogeochem. Cy., 10, 603-628, doi:10.1029/96GB02692, 1996.

Fontaine, S. and Barot, S.: Size and functional diversity of microbe populations control plant persistence and long-term soil carbon accumulation, Ecol. Lett., 8, 1075-1087, doi:10.1111/j.14610248.2005.00813.x, 2005.

Franklin, O., Högberg, P., Ekblad, A., and Ågren, G. I.: Pine forest floor carbon accumulation in response to $\mathrm{N}$ and $\mathrm{PK}$ additions: bomb ${ }^{14} \mathrm{C}$ modelling and respiration studies, Ecosystems, 6, 644-658, doi:10.1007/s10021-002-0149-x, 2003.

Frantz, J. M., Cometti, N. N., and Bugbee, B.: Night temperature has a minimal effect on respiration and growth in rapidly growing plants, Ann. Bot.-London, 94, 155-166, doi:10.1093/aob/mch122, 2004.

Frey, S. D., Lee, J., Melillo, J. M., and Six, J.: The temperature response of soil microbial efficiency and its feedback to climate, Nature Clim. Change, 3, 395-398, doi:10.1038/nclimate1796, 2013.

Frost, P. C., Evans-White, M. A., Finkel, Z. V., Jensen, T. C., and Matzek, V.: Are you what you eat? Physiological constraints on organismal stoichiometry in an elementally imbalanced world, Oikos, 109, 18-28, doi:10.1111/j.00301299.2005.14049.x, 2005.

Gerber, S., Hedin, L. O., Oppenheimer, M., Pacala, S. W., and Shevliakova, E.: Nitrogen cycling and feedbacks in a global dynamic land model, Global Biogeochem. Cy., 24, GB1001, doi:10.1029/2008GB003336, 2010.

German, D. P., Marcelo, K. R. B., Stone, M. M., and Allison, S. D.: The Michaelis-Menton kinetics of soil extracellular enzyme in response to temperature: a cross-latitudinal study, Glob. Change Biol., 18, 1468-1479, doi:10.1111/j.1365-2486.2011.02615.x, 2012.

Gillabel, J., Cebrian-Lopez, B., Six, J., and Merckx, R.: Experimental evidence for the attenuating effect of SOM protection on tem- 
perature sensitivity of SOM decomposition, Glob. Change Biol., 16, 2789-2798, doi:10.1111/j.1365-2486.2009.02132.x, 2010.

Hararuk, O., Smith, M. J., and Luo, Y.: Microbial models with data-driven parameters predict stronger soil carbon responses to climate change, Glob. Change Biol., 21, 2439-2453, doi:10.1111/gcb.12827, 2015.

Kivlin, S. N., Waring, B. G., Averill, C., and Hawkes, C. V.: Tradeoffs in microbial carbon allocation may mediate soil carbon storage in future climates, Front. Microbiol., 4, 261, doi:10.3389/fmicb.2013.00261, 2013.

Lawrence, C. R., Neff, J. C., and Schimel, J. P.: Does adding microbial mechanisms of decomposition improve soil organic matter models? A comparison of four models using data from a pulsed rewetting experiment, Soil Biol. Biochem., 41, 19231934, doi:10.1016/j.soilbio.2009.06.016, 2009.

Li, C.: The DNDC model, in: Evaluation of Soil Organic Matter Models, edited by: Powlson, D. S., Smith, P., and Smith, J. U., Springer, Berlin, 263-268, 1996.

Li, J., Wang, G., Allison, S. D., Mayes, M. A., and Luo, Y.: Soil carbon sensitivity to temperature and carbon use efficiency compared across microbial-ecosystem models of varying complexity, Biogeochemistry, 119, 67-84, 2014.

Manzoni, S., Taylor, P., Richter, A., Porporato, A., and Ågren, G. I.: Environmental and stoichiometric controls on microbial carbon-use efficiency in soils, New Phytol., 196, 79-91, doi:10.1111/j.1469-8137.2012.04225.x, 2012.

Merchant, S. S. and Helmann, J. D.: Elemental economy: microbial strategies for optimizing growth in the face of nutrient limitation, Adv. Microb. Physiol., 60, 91-210, doi:10.1016/B978-012-398264-3.00002-4, 2012.

Menge, D. N. L., Pacala, S. W., and Hedin, L. O.: Emergence and maintenance of nutrient Limitation over multiple timescales in terrestrial ecosystems, The American Naturalist, 173, 164-175, 2009

Molina, J. A. E., Hadas, A., and Clapp, C. E.: Computer simulation of nitrogen turnover in soil and priming effect, Soil Biol. Biochem., 22, 349-353, doi:10.1016/0038-0717(90)90112D, 1990 .

Moorhead, D. L., Lashermes, G., and Sinsabaugh, R. L.: A theoretical model of $\mathrm{C}$-and $\mathrm{N}$-acquiring exoenzyme activities, which balances microbial demands during decomposition, Soil Biol. Biochem., 53, 133-141, doi:10.1016/j.soilbio.2012.05.011, 2012.

Moorcroft, P. R., Hurtt, G. C., and Pacala, S. W.: A method for scaling vegetation dynamics: The Ecosystem Demography Model (ED), Ecological Monographs, 71, 557-586, 2001.

Parton, W. J., Schimel, D. S., Cole, C. V., and Ojima, D. S.: Analysis of factors controlling soil organic matter levels in Great Plains grasslands, Soil Sci. Soc. Am. J., 51, 1173-1179, doi:10.2136/sssaj1987.03615995005100050015x, 1987.

Pretzsch, H., Biber, P., Schütze, G., Uhl, E., and Rötzer, T.: Forest stand growth dynamics in Central Europe have accelerated since 1870, Nat. Commun., 5, 1-10, doi:10.1038/ncomms5967, 2014.

Russell, J. B. and Cook, G. M.: Energetics of bacterial growth: balance of anabolic and catabolic reactions, Microbiol. Rev., 59, 48 62, 1995.

Schmidt, M. W. I., Torn, M. S., Abiven, S., Dittmar, T., Guggenberger, G., Janssens, I. A., Kleber, M., Kögel-Knabner, I., Lehmann, J., Manning, D. A. C., Nannipieri, P., Rasse, D.
P., Weiner, S., and Trumbore, S. E.: Persistence of soil organic matter as an ecosystem property, Nature, 478, 49-56, doi:10.1038/nature10386, 2011.

Schmidt, S. K., Costello, E. K., Nemergut, D. R., Cleveland, C. C., Reed, S. C., Weintraub, M. N., Meyer, A. F., and Martin, A. M.: Biogeochemical consequences of rapid microbial turnover and seasonal succession in soil, Ecology, 88, 13791385, doi:10.1890/06-0164, 2007.

Schimel, J. P. and Weintraub, M. N.: The implications of exoenzyme activity on microbial carbon and nitrogen limitation in soil: a theoretical model, Soil Biol. Biochem., 35, 549-563, doi:10.1016/S0038-0717(03)00015-4, 2003.

Sinsabaugh, R. L., Manzoni, S., Moorhead, D. L., and Richter, A.: Carbon use efficiency of microbial communities: stoichiometry, methodology and modelling, Ecol. Lett., 16, 930-939, doi:10.1111/ele.12113, 2013.

Sistla, S. A., Rastetter, E. B., and Schimel, J. P.: Responses of a tundra system to warming using SCAMPS: a stoichiometrically coupled, acclimating microbe-plant-soil model, Ecol. Monogr., 84, 151-170, doi:10.1890/12-2119.1, 2014.

Sitch, S., Smith, B., Prentice, I. C., Arneth, A., Bondeau, A., Cramer, W., Kaplan, J. O., Levis, S., Lucht, W., Sykes, M. T., Thonicke, K., and Venevsky, S.: Evaluation of ecosystem dynamics, plant geography, and terrestrial carbon cycling in the LPJ dynamic global vegetation model, Glob. Change Biol., 9, 161-185, doi:10.1046/j.1365-2486.2003.00569.x, 2003.

Stark, J. M. and Hart, S. C.: High rates of nitrification and nitrate turnover in undisturbed coniferous forests, Nature, 385, 61-64, doi:10.1038/385061a0, 1997.

Stone, M. M., Weiss, M. S., Goodale, C. L., Adams, M. B., Fernandez, I. J., German, D. P., and Allison, S. D.: Temperature sensitivity of soil enzyme kinetics under N-fertilization in two temperate forests, Glob. Change Biol., 18, 1173-1184, 2012.

Tang, J. Y.: On the relationships between the Michaelis-Menten kinetics, reverse Michaelis-Menten kinetics, equilibrium chemistry approximation kinetics, and quadratic kinetics, Geosci. Model Dev., 8, 3823-3835, doi:10.5194/gmd-8-3823-2015, 2015.

Tang, J. Y. and Riley, W. J.: Weaker soil carbon-climate feedbacks resulting from microbial and abiotic interactions, Nature Clim. Change, 5, 56-60, doi:10.1038/nclimate2438, 2015.

Thornley, J. H. M.: Plant growth and respiration re-visited: maintenance respiration defined-it is an emergent property of, not a separate process within, the system-and why the respiration: photosynthesis ratio is conservative, Ann. Bot.-London, 108, 13651380, doi:10.1093/aob/mcr238, 2011.

Todd-Brown, K. E. O., Hopkins, F. M., Kivlin, S. N., Talbot, J. M., and Allison, S. D.: A framework for representing microbial decomposition in coupled climate models, Biogeochemistry, 109, 19-33, doi:10.1007/s10533-011-9635-6, 2012.

Todd-Brown, K. E. O., Randerson, J. T., Post, W. M., Hoffman, F. M., Tarnocai, C., Schuur, E. A. G., and Allison, S. D.: Causes of variation in soil carbon simulations from CMIP5 Earth system models and comparison with observations, Biogeosciences, 10, 1717-1736, doi:10.5194/bg-10-1717-2013, 2013.

Tucker, C. L., Bell, J., Pendall, E., and Ogle, K.: Does declining carbon-use efficiency explain thermal acclimation of soil respiration with warming?, Glob. Change Biol., 19, 252-263, doi:10.1111/gcb.12036, 2013. 
Van Bodegom, P.: Microbial maintenance: a critical review on its quantification, Microbial. Ecol., 53, 513-523, doi:10.1007/s00248-006-9049-5, 2007.

Van Veen, J., Ladd, J., and Frissel, M.: Modelling C and N turnover through the microbial biomass in soil, Plant Soil, 76, 257-274, 1984.

Vetter, Y. A., Deming, J. W., Jumars, P. A., and Krieger-Brockett, B. B.: A predictive model of bacterial foraging by means of freely released extracellular enzymes, Microbial Ecol., 36, 7592, 1998.

Wagai, R., Kishimoto-Mo, A. W., Yonemura, S., Shirato, Y., Hiradate, S., and Yagasaki, Y.: Linking temperature sensitivity of soil organic matter decomposition to its molecular structure, accessibility, and microbial physiology, Glob. Change Biol., 19, 11141125, doi:10.1111/gcb.12112, 2013.

Wang, G. and Post, W. M..: A note on the reverse MichaelisMenten kinetics, Soil Biol. Biochem., 57, 946-949, doi:10.1016/j.soilbio.2012.08.028, 2013.

Wang, G., Post, W. M., and Mayes, M. A.: Development of microbial-enzyme-mediated decomposition model parameters through steady-state and dynamic analyses, Ecol. Appl., 23, 255272, doi:10.1890/12-0681.1, 2013.

Wang, Y. P., Chen, B. C., Wieder, W. R., Leite, M., Medlyn, B. E., Rasmussen, M., Smith, M. J., Agusto, F. B., Hoffman, F., and Luo, Y. Q.: Oscillatory behavior of two nonlinear microbial models of soil carbon decomposition, Biogeosciences, 11, 18171831, doi:10.5194/bg-11-1817-2014, 2014.
Wieder, W. R., Bonan, G. B., and Allison, S. D.: Global soil carbon projections are improved by modelling microbial processes, Nature Clim. Change, 3, 909-912, doi:10.1038/nclimate1951, 2013.

Wieder, W. R., Grandy, A. S., Kallenbach, C. M., and Bonan, G. B.: Integrating microbial physiology and physio-chemical principles in soils with the MIcrobial-MIneral Carbon Stabilization (MIMICS) model, Biogeosciences, 11, 3899-3917, doi:10.5194/bg11-3899-2014, 2014a.

Wieder, W. R., Boehnert, J., and Bonan, G. B.: Evaluating soil biogeochemistry parameterizations in Earth system models with observations, Global Biogeochem. Cy., 28, 211-222, doi:10.1002/2013GB004665, 2014b.

Wieder, W. R., Allison, S. D., Davidson, E. A., Georgiou, K., Hararuk, O., He, Y., Hopkins, F., Luo, Y., Smith, M. J., Sulman, B., Todd-Brown, K., Wang, Y., Xia, J., and Xu, X.: Explicitly representing soil microbial processes in Earth system models, Global Biogeochem. Cy., 29, 1782-1800, 2015a.

Wieder, W. R., Grandy, A. S., Kallenbach, C. M., Taylor, P. G., and Bonan, G. B.: Representing life in the Earth system with soil microbial functional traits in the MIMICS model, Geosci. Model Dev., 8, 1789-1808, doi:10.5194/gmd-8-1789-2015, 2015b. 